\title{
The Eucalyptus grandis chloroplast proteome: leaf development and seasonal variations
}

\author{
Amanda Cristina Baldassi ${ }^{1 \uparrow}$ and Tiago Santana Balbuena ${ }^{1 * \&}$
}

${ }^{1}$ Department of Agricultural, Livestock and Environmental Biotechnology, São Paulo State University (UNESP), School of Agriculture and Veterinary Sciences, Jaboticabal, São Paulo, Brazil.

*Corresponding author

E-mail: tiago.balbuena@unesp.br (TSB)

I This author carried out the experiment, processed and analyzed the data and wrote the manuscript with support from T. S. B. All authors discussed the results and contributed to the final manuscript.

\&This author designed the study, supervised the project and contributed to the interpretation of the results. All authors discussed the results and contributed to the final manuscript.

\section{Abstract}

Chloroplast metabolism is very sensitive to environmental fluctuations and is intimately related to plant leaf development. Characterization of the chloroplast proteome dynamics may contribute to enlarge the understanding on plant adaptation to different climate scenarios and leaf development processes. Herein, we carried out a discovery-driven proteome analysis of the Eucalyptus grandis chloroplast proteome during leaf maturation and throughout different seasons of the year. The chloroplast proteome from young leaves differed the most from all assessed samples. Most up-regulated proteins identified in mature and young leaves were those related to catabolic-redox signaling and biogenesis processes, respectively. Seasonal dynamics revealed unique proteome features in the autumn and spring periods. The most abundant chloroplast protein in 
32 humid (wet) seasons (spring and summer) was a small subunit of

33 RuBisCO, while in the dry periods (fall and winter) the proteins that

34 showed the most pronounced accumulation were associated with photo-

35 oxidative damage, Calvin cycle, shikimate pathway, and detoxification.

36 Our investigation of the chloroplast proteome dynamics during leaf

37 development revealed significant alterations in relation to the maturation event. Our findings also suggest that transient seasons induced the most pronounced chloroplast proteome changes over the year. This study contributes to a more comprehensive understanding on the subcellular mechanisms that lead to plant leaf adaptation and ultimately to Eucalyptus grandis productivity. Mass spectrometric data are available via ProteomeXchange under identifier PXD029004.

\section{Introduction}

Chloroplast is a subcellular compartment in which solar radiation is used to generate sugar compounds in a complex process named photosynthesis. It is also the cellular compartment that hosts several other metabolic processes that are essential for plant survival, such as synthesis of lipids, fatty acids, vitamins, hormones, secondary metabolites, in addition to most of the proteogenic amino acids found in plant cells, like methionine, cysteine, and threonine [1-5]. 
Plastids are composed of inner and outer membrane, stroma,

54 thylakoidal membrane, and lumen [5]. Chloroplast genome encodes 55 approximately $120-130$ proteins, whilst most of the chloroplast proteome, 56 comprising approximately 2000 proteins, are synthesized in the cytosol, 57 and imported into the organelle through the envelope membranes [6-7]. Chloroplast genome varies from $107 \mathrm{~kb}$ to $218 \mathrm{~kb}$ in size depending on the plant species [8].In Eucalyptus grandis, the chloroplast genomepresents approximately $160 \mathrm{~kb}$ [9-10].

As chloroplasts are very sensitive to environmental fluctuations, dynamic proteome changes may represent a key factor for understanding 63 their responses to abiotic stresses [11]. The most recent chloroplast proteomics studieshave aimed to identify (1) changes induced by biotic and abiotic stresses [12-16], (2) mechanisms of remodeling and reprogramming of plant metabolism $[17,18],(3)$

(3) biogenesis and senescence [19-21], chloroplast development [22,23], in addition to (5) novel techniques for increasing proteome coverage [24-26]. to light,turninto mature chloroplasts with functional electron transport carriers, membrane channel proteins, and stromal enzymes that are able to capture, assimilate, and storage carbon [27]. During senescence, they differentiate from gerontoplasts, which lead to leaf yellowing, necrosis, and death [28]. Thereby, plastid development is intimately related to the 
development of the whole plant at different stages [32].The manipulation of several agronomic traits, e.g., photosynthetic rate, stomatal conductance, chlorophyll content, and PSII photochemical, has been reported to delay the senescence process and increase plant biomass, seed yield, seed protein composition, and tolerance to abiotic stresses [33, 34, 35].

Plants are sessile organisms, which means that they are subjected to seasonal climate alterations and adverse environmental conditions. Seasonal climate variations can drive plant growth and development, favoring a metabolic adaptation of the life cycle with changes in the environment [36]. Strong seasonal effects have been observed on the growth of perennial plants due to varying availability of water, light, nutrients, and temperature [37, 38]. In Populus species, for instance, seasonal phenology is largely related to changes in growth and development, such as bud flush in spring followed by vegetative growth in the summer; while during the fall, the trees present growth inhibition and bud formation, followed by leaf senescence, abscission, and cold acclimation before the winter season [39]. Regarding photosynthetic physiological changes, studies ahve revealed that the quantum efficiency seasonal pattern shows minimal values in the spring, increasing during the summer, and reaching maximal values in the fall followed by a decrease in the winter $[40,41]$. 
97 development process and seasonal metabolic changes can provide valuable

98 information forincreasing plant productivity and learning the mechanisms

99 that lead to plant adaptation. This is the first exploratory investigation on

100 proteome changes during leaf development and seasonal variations in

101 Eucalyptus grandis young plants on an organellar level. This research

102 aimed to carry out an exploratory analysis of chloroplast alterations during 103 leaf development and seasonal variations in the Eucalyptus grandis 104 chloroplast proteome.

\section{Material and Methods}

\section{Plant cultivation and sampling}

Eucalyptus grandis plants were cultivated at the "Horto Florestal" of the São Paulo State University (Jaboticabal - SP, Brazil) using a

110 randomized block design experiment with $2 \mathrm{~m} \times 3 \mathrm{~m}$ spacing. Fertilization 111 and irrigation were carried out twice a month and three times a week,

112 respectively. The region climate is defined as tropical and characterized by 113 rainfalls concentrated in the summer and dry winter [42]. 114 Agrometeorological data were collected daily at the UNESP environmental station (S1 Table). 
For the leaf developmental assay, three biological replicates,

117 comprising five randomly selected branches, were divided into three

118 different regions (young, middle, and mature), according to the

119 fluorescence data (FV/FM) and chlorophyll relative quantification (CCI),

120 and used to assess proteome changes throughout development (S1A Fig).

121 For the chloroplast proteome seasonal variation assay, four biological

122 replicates, comprising forty leaves from the first until the fifth node, were

123 assessed in all four seasons from August/2019 to August/2020 (S1B Fig).

124 For both assays using leaf sampling, plant material was immediately 125 transferred to ice before isolating the chloroplasts, as described in the next 126 sections.

\section{Fluorescence Measurement and Chlorophyll Relative}

\section{Quantification}

Fluorescence analysis was performed on the fluorometer FluorPen

FP 100 (Photon Systems Instruments) assessing the adaxial surface of

132 leaves from different regions of the 15 branches. The fluorescence values

133 obtained directly from the device were used to assess the potential quantum

134 efficiency of photosystem II (FV/FM). Relative chlorophyll was quantified on CCM-200 equipment (Opti-Sciences), and the adaxial surface of leaves

136 from different regions of the 15 branches was examined. The CCI 
137 (chlorophyll content index) values obtained directly from the device were used to assess relative chlorophyll quantification. Statistical analysis was performed according to the ANOVA test $(\mathrm{p}<0.05)$, and Tukey's test was used for comparison among different leaves.

\section{Chloroplast proteome isolation}

Aliquots of six grams of leaves were collected, fine sliced, and

transferred to tubes containing $20 \mathrm{~mL}$ of chloroplast isolation buffer (CIB,

Turrax) and filtered through a nylon membrane. The processed material

v/v) Percoll density gradient. After washing, the chloroplast pellet was resuspended in a protein extraction buffer (Thiourea 2M; CHAPS; Tristhe lysis of intact chloroplasts was carried out through 20 cycles of

$0.1 \%$ DTT).

\section{Total leaf proteome isolation}


159 the total leaf proteome, intact leaves were frozen in $-80^{\circ} \mathrm{C}$ and grinded in

160 Tris extraction buffer (125 mM Tris, $\mathrm{pH}$ 6.8, 20\% glycerol, 1\% SDS, 0.1\%

161 DTT). Upon centrifugation at $4^{\circ} \mathrm{C}$ for $15 \mathrm{~min}$, the supernatant was

162 transferred to a clean tube and the proteins were precipitated in cold 163 acetone for 16 hours at $-30{ }^{\circ} \mathrm{C}$. Finally, the proteins were solubilized in Tris 164 buffer before protein quantification assay.

\section{Protein quantification assay and SDS-PAGE}

curve as reference. Aliquots of $50 \mu \mathrm{g}$ of proteins were separated for 1 hour by denaturing electrophoresis on a polyacrylamide gel containing sodium dodecyl sulfate (SDS-PAGE) to obtain a single band. The electrophoretic system was composed of a stacking gel (5\%) and a separation gel (12.5\%). The single protein band was excised from the gel and subjected to in-gel digestion.

\section{Mass spectrometry analysis}

Proteins were in-gel digested using trypsin at 1:10 proportion

177 (trypsin:protein) [43]. To clean up the peptide samples, extracts were filtered in an acetate cellulose membrane (Spin-X, Corning) by 
according to the manufacturer's protocol. The amount of lug of extracted

peptides was analyzed through liquid chromatography coupled to a tandem

mass spectrometer. Tryptic peptides were resuspended in $\mathrm{H}_{2} \mathrm{O}$ containing

$0.1 \%$ formic acid and separated in an EASY-nLC1000 chromatographic system (Thermo Fisher Scientific) for 95 minutes using a C18 nano-column under a constant flow of $400 \mathrm{~nL} / \mathrm{min}$ and increasing concentrations of acetonitrile ( 7 to $30 \%$ over $70 \mathrm{~min}$ and then $70 \%$ in $25 \mathrm{~min}$ ). The peptides

were ionized through electrospray $(3.5 \mathrm{kV})$ and the mass spectrometer (Q-

Exactive, Thermo Fisher Scientific) was operated in data-dependent

acquisition mode according to a top 20 acquisition method with dynamic

exclusion time adjusted to five seconds. Full scans and MS/MS scans were

acquired with resolutions equal to 70,000 and 35,000 FWHM (full width at

half maximum), respectively. The MS/MS spectra were generated from

HCD fragmentation (high-energy collision dissociation) of the precursor peptide ions isolated under $35 \mathrm{eV}$ collision energy.

\section{Protein identification}

The peptides and protein inferences were identified through stringent searches of experimental data against the protein database Eucalyptus 

ions, oxidation of methionines and carbamidomethylation of cysteines -

203 selected as dynamic and static modifications, respectively. Maximum

204 missed cleavages of 2 and false-discovery rate adjusted to $1 \%$. Relative 205 protein of the chloroplast proteins were quantified based on the label free206 based approach (LFQ intensity). Relative abundance of total leaf proteins 207 was obtained following the NSAF ("normalized spectral abundance 208 factor") approach [45]. Mass spectrometry proteomics data are currentlystored on the ProteomeXchange Consortium via PRIDE partner repository under dataset identifier PXD029004.

212 It is worthnoting that the ProteomeXchange dataset PXD029004 has not 213 yet been publicly released,therefore, reviewers may require the following 214 information to access mass spectrometric data:

215 Username: reviewer_pxd029004@ebi.ac.uk

216 Password: WwsYFMTy

Data processing and statistical analysis were carried out on the

221 Perseus software (v. 1.6.15.0) [46]. Firstly, all contaminants and reverse 222 sequences were removed from data analysis. Subsequently, label-free 
was considered a true hit if identified in at least two out of three replicates.

225 Missing values imputation was carried out from the normal distribution

226 curve from each biological replicate. The means of ANOVA test and

227 Tukey comparison test $(\mathrm{p}<0.05)$ were used in the comparative analyses.

Multivariate analyses were carried out with differentially abundant proteins

229 for both assays on the Perseus software. For PCA and hierarchical

230 clustering, data were z-score normalized. Hierarchical clustering was performed using Euclidean distance and complete linkage. carried out using the Blast2GO platform $(p<0,05)$ [47]. the ten most representative level-four biological processes were considered in the functional characterizationaiming to balance between a comprehensive overview and detailed information on the targeted biological process. Level four was chosen forincluding photosynthesis, an important process in the context of leaves and chloroplasts.

\section{Subcellular prediction}

242 location and chloroplast proteome repositories to assess and confirm the 243 cellular location of the identified proteins. For this purpose, a protein was 244 considered plastidial if identified by at least one of the subcellular 
246 at least one homologous protein in any of the databases used - PPDB

247 [50]or AT-Chloro [51].

\section{Results and Discussion}

Before performing any description or comparative proteome analysis, we decided to verify the efficiency of the chloroplast enrichment strategy used herein. For this purpose, we compared the abundance levels, in terms of NSAF and LFQ intensities, of a well-known chloroplast proteoform Eucgr.C03525.1 (Ribulose-bisphosphate carboxylase - RBCL) against five potential mitochondrial contaminants commonly found in chloroplast isolations (Table 1). Quantitative analysis indicated that the chloroplast proteoform was enriched upon the isolation process, whereas

258 the mitochondrial proteoforms presented a decrease in the abundance

259 levels. These results indicated that our chloroplast isolation and enrichment 260 strategy was effective in reducing the number of cross-contaminants,as well as in the enrichment process of chloroplast-related proteins in the target samples.

Table 1. Enrichment analysis of chloroplast proteins in Eucalyptus grandis using a 

extract, Chloro: Chloroplast protein extract, FD: Fold-Change.

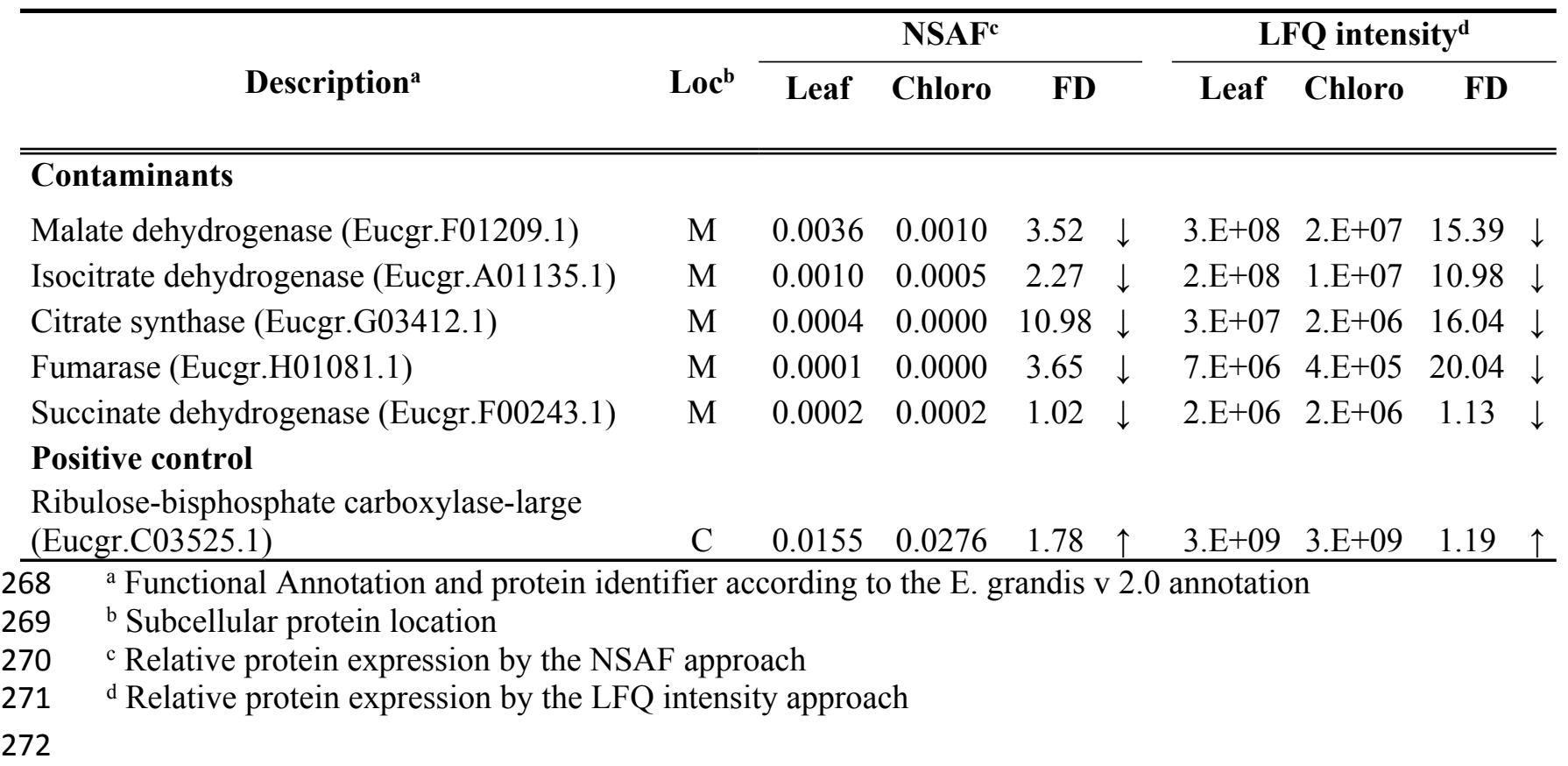

\section{Photosynthetic proteins comprise most of the Eucalyptus}

\section{grandis chloroplast proteome.}

Aiming to illustrate a general overview of the chloroplast proteome

276 isolated from Eucalyptus grandis leaves, we compiled the identification

277 datasets from both leaf development and seasonal experiments. The

278 combined analysis resulted in a stringent, non-redundant dataset of 431

279 chloroplast proteins (2S Table). Gene ontology analysis indicated that most

280 of the isolated proteins were involved in the "organonitrogen compound

281 metabolic process", "organic substance biosynthetic process", and

processes were the most prominent in terms of protein identifications, an 
286 The fraction of "photosynthetic process" related to proteins becomes even

287 more pronounced within the isolated proteome upon the analysis of the most abundant proteins identified in the entire experiment (Fig 1C). The RuBisCO small chain (Eucgr.J01502.2.p) was the most abundant protein identified herein, showing approximately 4000 MS/MS counts. The proteins involved in the photosystem II structure were also highly abundant: two extrinsic proteins (PsbO-2 - Eucgr.I01025.1.p and PsbQ-2 light-harvesting complex protein from the PSII (Eucgr.F04099.1.p) corresponding to 1500 to $3000 \mathrm{MS} / \mathrm{MS}$ counts (Fig 1C).

Regarding the suborganellar localization of the 431 chloroplast proteins, 137 proteins were present in the stroma compartment, whilst 135 were thylakoidal proteins. A total of 87 proteins were predicted in silicoto be located in the chloroplast outer membrane, and 13 identifications were found to be part of the chloroplast inner membrane. Finally, 52 proteins were located in the chloroplast lumen and 7 proteins herein identified had been previously reported as part of the plastoglobule structure (Fig 1D).

Fig 1. The Eucalyptus grandischloroplast proteome. Classification analysis, in terms of the number of identified proteins (A) and terms of the percentage of identified proteins (B), upon categorization using the "biological process" ontology; protein expression analysis of the Gene 
308 Ontology terms (C); number of protein identifications per chloroplast sub-

309 cellular compartment (D).

310

Chloroplast proteome reflects the physiological status in

Based on the varying Fv/Fm ratios and the differences observed from

the relative chlorophyll quantitation analysis (S2 Fig), we isolated the chloroplast proteome from young, middle, and mature leaves. Quantitative data from the isolated proteins were used to demonstrate the changes within this subcellular structure throughout the leaf development process. Pairwise analysis indicated that 61 proteins were considered to be differentially abundant over the development process, with the young chloroplast proteome as the most dissimilar of the three different regions (2A Fig). Fig, as the young leaf tissue presented the most significant variations concerning middle and mature regions. A study on sugarcane leaves have also demonstrated that physiological parameters, such as chlorophyll content, nitrogen content, and RubisCO activity, were greater and more consistent between mature and transition tissues than in young regions [52]. Clustering analysis allowed to classify the differentially abundant proteins (DAP) in three distinctive groups: up-regulated -17 proteins with 
proteins with lower abundance along the studied process, and an undefined

group, comprising 15 proteins with an unclear abundance pattern (2B Fig).

Fig 2. Multivariate analyses of the 61 differentially abundant chloroplast proteins isolated from young, middle, and mature Eucalyptus grandis leaves. Principal component analysis (A), clustering expression analysis (B), and functional categorization of the differentiallyregulated chloroplast proteins between young (down-regulated) and mature (up-regulated) (C). The z-score indicates the distance of the data compared to the mean value.

Proteins with higher abundance throughput leaf development comprised those involved in the antioxidant metabolism (APX4, CAT2, tAPX, and SODFe2), stress responses/protection against lipid peroxidation (IDH-V, MPC1, and CHL), and photosynthesis (PSBQ-2, PSBO-2, GAPB, and FTRA2). Additionally, proteins involved in post-transcriptional modifications (CBR), regulation of PSII (TLP), amino acid metabolism

349 Conversely, antioxidants and detoxification (TPX, AOR 1, and AOR2), and

350 photosynthesis (RCA, RBCS1, RBCS2, and PSBS) were observed during

351 leaf development in addition to lower abundance,in ribosomal proteins

biosynthetic (CRD1, PORA, THI1, PLP and IPP2, GSA1, LPD1, and FKB), folding, modification, and transport (TPR, HSC70-2 and CLPC1, 

abundance pattern or those presenting a transient increase or decrease in the abundance levels were found to be involved in the photosynthetic process and electron transport chain (LHB1, PSAF, and THOL), in addition to folding, modification, and transport (HSP70, HSP21, ENR2, OEP24A, and RABE1B) and biosynthetic processes (NDPK1, MEE32, and PSAT). Proteins responsible for peptide degradation/repair of photosynthetic machinery (PREP2 and FtsH), oxidoreductase, and protease (CHLP and ASP) were also clustered within such heterogeneous group (S3 Table). along leaf development, up and down-regulated proteins were crossreferenced to corresponding gene ontology terms. Functional categories revealed differences between the chloroplast protein groups (2C Fig). Leaf development induced "cellular catabolic processes" in Eucalyptus grandis chloroplasts for being the most representative category within the upregulated group. Responses to stress, mainly to oxidative stress and cellular detoxification, were the most abundant functional category in up-regulated throughout leaf development, based on the maturity of the photosynthetic apparatus and the higher photosynthesis rates in young leaves. In nonstressing conditions, mature leaves are expected to maintain cellular homeostasis with a dynamic balance between the light energy absorbed and energy consumption [53]. In mature leaves, generation of reactive oxygen 
377 species and changes in the redox state in the photosynthetic electron

378 transport chain are important indicators of operational retrograde signals.

379 The function of operational retrograde signaling differs from biogenic

380 signaling as it focuses on the adjustments and cellular homeostasis of the

381 chloroplast in response to different perturbations and developmental cues [54].

Conversely, the most representative functional class identified in the chloroplast down-regulated protein group (i.e., abundant in young leaves) were involved with cellular and organic biosynthetic processes, being the most representative in the "organic substance biosynthetic process" and the "nitrogen compound metabolic process". These results are under the developmental stage of the young leaves used here. As plastids are intimately related to developmental and environmental signals, chloroplasts from young leaves were expected to reflect the biogenesis processes, which involves large-scale gene transcription followed by synthesis, importing, and assemblies of biogenesis proteins, such as those involved in plastid translation apparatus and enzymes in the synthesis of isoprenoids and tetrapyrroles [55]. In turn, in mature leaves, redox-related proteins comprised most of the differentially regulated proteins; the only category suggested by gene ontology analysis in young leaves for "cell redox homeostasis" comprised only 3\% of all down-regulated proteins. A study on the developmental dynamics of maize leaves also found up-regulated 
genes that encode enzymes involved in diverse biosynthetic processes in

400 young leaves. Similarly, in mature leaves, the up-regulated genes

401 predominant encoded Calvin cycle, redox regulation, and the light reactions

402 of photosynthesis [55].

403

For better insights into the changing patterns of the up-and down-

404 regulated proteins, we classified the chloroplast proteins into three

405 expression trends, as shown in Fig 3. The early responsive proteins

406 comprised the subset with a drastic change in the abundance level in

407 middle leaf tissues,remaining at similar levels in both mature and young

408 leaves. Conversely, late responsive proteins showed a drastic abundance

change only in the contrasting leaf tissue (young or mature leaves). We

considered as almost linear responsive the proteins without drastic changes

411 throughout the leaf development process, but with a significant change

412 between mature and young tissues.

Early up-regulated proteins (i.e., early increased abundance along

414 leaf development) were identified as follows: Mitochondrial pyruvate

carrier, Isocitrate dehydrogenase V, Ferredoxin/thioredoxin reductase

417 protein family (MPC1, IDH-V, FTRA2, PYD2, CA1, and GCT). The most

418 pronounced increase occurred in the Pyrimidine 2 (PYD2) protein from

419 young to middle tissues. This protein acts in beta-alanine biosynthesis and

420 nitrogen recycling from pyrimidines to general nitrogen metabolism [56]. 
Late up-regulated proteins (i.e., late increased abundance along leaf

422 development) were identified as follows: Photosystem II subunit Q-2,

423 Glyceraldehyde-3-phosphate dehydrogenase B subunit, and Chloroplast

424 lipocalin (PSBQ-2, GAPB, CHL). The most pronounced increase in

425 abundance chloroplast lipocalin (CHL) presented. This protein acts in the

426 protection of thylakoidal membrane lipids against reactive oxygen species,

427 especially singlet oxygen, induced by high light and drought stresses occurring mainly at early stress stages in Arabidopsis [57]. It has also been reported that stress conditions cause the $\mathrm{CHL}$ to protect the thylakoid membrane by facilitating a sustained non-photochemical quenching (NPQ) in the LHCII in Arabidopsis [58]. A nearly increasing linear responsive pattern throughout leaf development was found in the following chloroplast proteins: Ascorbate peroxidase 4, Catalase 2, Thylakoidal ascorbate peroxidase, Fe superoxide dismutase 2, Thylakoid lumen $18.3 \mathrm{kDa}$ protein,

Photosystem II subunit O-2, Chloroplast RNA binding, and Plastid-lipid associated protein PAP/fibrillin (APX4, CAT2, tAPX, SODFe2, TLP, PSBO-2, CBR, and FIB4).

439 leaf development) was the largest trend group according to our categorization (16 proteins) comprising proteins involved in the biosynthesis of fatty acids, isoprenoids, and amino acids (LPD1, IPP2, and 442 PLP), chloroplast RNA binding proteins (RBD1, RBD2, and DAG), 
ribosomal proteins acting in the biosynthesis of thylakoid membrane and thylakoid curvature (RPS1 and CURT1C), transport, modification and

445 import into the chloroplast (LTP2, TPR, and CLPC1), proteins associated 446 with detoxification (TPX1, AOR1, and AOR2), binding cofactors (ENR1), 447 and sucrose metabolism (ALD). a nearly linear down-regulated responsive trend appeared in 10 protein sequences showed that act in carbon fixation RubisCO (RCA, RBCS1, and RBCS2), chlorophyll biosynthesis (CRD1, PORA, GSA1), transport and folding (LTP1 and HSC70-2), and structural ribosomal proteins (RPL13 and PRPL1). In turn, only two proteins showed a late down-regulated pattern, pfkB-like carbohydrate kinase family protein and Thiazole biosynthetic enzyme, chloroplast (FKB and THI1).

Fig 3. Expression trends of the differentially regulated chloroplast proteins. Up-regulated proteins increased abundance throughout leaf development, while down-regulated proteins decreased abundance during leaf development.

In conclusion, while investigating the chloroplast proteome changes proteome regarding the maturation process. Out of the 431 proteins isolated from the chloroplast material, 61 showed significant changes in the abundance throughout leaf development. There was no clear bias towards a unique change in the proteome composition; instead, we found distinct patterns of protein accumulation. In addition to pinpointing proteins with 
467 pronounced changes ranging the studied phenomenon, through a

468 quantitative proteomics approach, we also specified the most particular

469 biological and metabolic processes involving leaf development. However,

470 as the proteome of any living entity is constantly changing, we also decided

471 to investigate the undisturbed (i.e., without inducing anthropogenic

472 alterations due to external stimulus) sub-cellular proteome dynamics by

473 analyzing the seasonal changes occurring in the chloroplast proteome of

474 Eucalyptus grandis plants cultivated at the State of Sao Paulo Forest

475 Nursery between September 2019 and August 2020.

\section{Transient seasons induce the most pronounced chloroplast}

\section{proteome changes}

Meteorological data revealed only small changes in the mean and maximum temperatures recorded throughout the study period, with the minimum diurnal temperature ranges observed during the summer season.

Precipitation analysis revealed extremely dry fall and winter seasons and mean monthly rainfall of almost $10 \mathrm{~mm}$ over the summer (Fig 4A).

Multivariate analysis of the E. grandis chloroplast proteomes suggested that both the fall- and the spring-related samples presented the most dissimilar profiles of the studied seasons (Fig 4B). This is likely to be 

followed by vegetative growth in summer. In turn, during the fall, the trees presented growth cessation and bud formation, followed by leaf senescence and abscission, in addition to cold acclimation for the winter [39]. Our comparative proteome analysis revealed that 41 proteins were differentially regulated across the seasons of the year in E. grandis (4S Table).

Fig 4. Meteorological data recorded at the Sao Paulo State University Forest Nursery during Eucalyptus grandis cultivation. Changes in temperature and rainfall rates between August 2019 and September 2020 (A). Multivariate analysis of the chloroplast proteome samples collected in the summer, fall, winter, and spring (B). seasons (fall and spring) presented the most dissimilar profiles, it is worthhighlighting the clusters that showed the most expressive differences in these specific periods.

508 values in the spring season. Proteins are related to light-harvesting complex, carbonyl detoxification, folding and modifications, carbohydrate

510 biosynthesis, hydrolases, amino acid precursors, and ATP carriers.

511 Conversely, Cluster 5 is composed of 6 proteins that showed higher 
512 abundance in the spring. Most of these identifications are associated with

513 RuBisCO regulation to enhance photosynthetic capacity. Other

514 identifications are responsible for lipid transport, protein modification, and

515 translation (Fig 5B).

Other studies have revealed that quantum efficiency seasonal pattern

517 has minimal values in the spring, increasing over the summer, reaching

518 maximal values in thefall, and finallydecreasing in the winter [40, 41].Such

519 scenario is demonstrated in Cluster 1, with proteins LHB1 and LHCB4,

520 which participate in the first steps of photosynthesis and are very efficient

521 in capturing light energy and transforming light into chemical energy [59].

522 Photosynthetic capacity in plants has also been reported to fluctuate with

523 increased levels throughout leaf development, reaching its peak in the

524 spring or early summer, and remaining stable or gradually declining over

525 the summer [60-62]. Such pattern appears in Cluster 5,with RuBisCO-

526 related proteins (RCA, RBCS1, and 2). Leaf fluorescence and

527 photosynthesis are expected to increaseover the spring, especially in

528 chlorophyll content. In the fall, these parameters are reduced when

529 associated with leaf physiological properties such as leaf aging and 530 senescence [63].

531 Cluster 4 presented the highest abundance for the fall season (Fig 
534 addition to two histones that play an important role in regulating 535 transcription and DNA repair and replication.

As previously described, trees undergo growth cessation and

537 establish dormancy before the onset of winter over a transition season. Low

538 temperatures were found to facilitate photoinhibition but not necessarily to

539 cause it [64];in addition, downregulation of Calvin-Benson cycle activity

540 and gas exchange precedes the reorganization of photosynthetic apparatus

541 in thylakoid membrane during the fall [65]. All these events are partially

542 related to PSII regulation and corroborate our analysis, where we found an

543 up-regulated protein related to the regulation of PSII in Cluster 4.

544 Furthermore, a plant epigenome is very responsive to changes in the

environment, and variations in epigenetic silencing mechanisms are among

546 the key factors that assist plants to adapt to different climate conditions

547 [66]. DNA methylation and histone modifications associated with

548 chromatin remodeling were reported to be the major changes

549 occurringthroughout dormancy season transitions [67]. The up-regulation

550 of two histones in the falloccuring in Cluster 4 could be associated with

551 these epigenetics events.

553 Fig 5. Differentially abundant proteins identified in Eucalyptus grandis

554 chloroplasts in different seasons of the year. Hierarchical clustering (A)

555 andprotein abundance trends (B). The z-score indicates the distance of the

556 data compared to the mean value. 

pronounced synthesis in each season, we carried out a fold-change analysis,as shown in Fig 6. The red boxes indicate proteins with significant

561 change equal or higher than 2-folds, blue boxes show significant change equal or higher than 5-folds, and white boxes point to proteins with change lower than 2-folds.

In Lolium perenne, the $\mathrm{RbcS}$ transcripts reached the highest levels over the spring, gradually decreasing between the summer and winter [69].

570 Similarly, all photosynthetic parameters measured in Quercus coccinea

571 Muench (scarlet oak) showed a peak in the late summer, followed by a 572 sharp decline in the fall [70].

575 Eucalyptus grandis leaves in studies seasons. Red boxes indicate proteins 576 with significant change higher than 2-folds. Blue boxes indicate a 577 significant change higher than 5 -folds. White boxes indicate proteins with 578 change lower than 2-folds.

582 rich family protein) is a PSII-associated proline-rich protein that 
The PORA protein (Protochlorophyllide oxidoreductase A) catalyzes the chlorophyll $\mathrm{a}$ and $\mathrm{b}[72,73]$. In addition to its role in chlorophyll

biosynthesis, PORA can also exert a photoprotective actionin the transition from dark to light [74], whereas theTriosephosphate isomerase enzyme (TPI) interconverts glyceraldehyde 3-phosphate (G3P) in the Calvin cycle placed in chloroplasts. Up-regulation of TPI in the winter has been reported in experiments performed on tubers and Eucalyptus grandis bark $[75,76]$.

The bifunctional enzyme MEE32 (dehydroquinate dehydratase, putative/shikimate dehydrogenase) is responsible for steps three and four of the shikimate pathways, catalyzing the dehydration of dehydroquinate to dehydroshikimate and the reversible reduction of dehydroshikimate to shikimate, respectively. Transgenic lines of tobacco with suppressed

MEE32 gene displayed severe growth retardation and reduced content of aromatic amino acids and downstream products such as lignin and chlorogenic acid [77]. In Eucalyptus camaldulensis, it confers aluminum tolerance [78]. AOR protein (Oxidoreductase, zinc-binding dehydrogenase

602 family protein) detoxify $\alpha, \beta$-unsaturated carbonyls by reducing a highly 603 electrophilic $\alpha, \beta$-unsaturated bond using $\mathrm{NAD}(\mathrm{P}) \mathrm{H}[79,80]$. It favors the 604 detoxifying of stromal lipid peroxide-derived reactive carbonyls (RCs) 
605

606

607

608

609

610

611

612

613

614

615

616

617

618

619

620

621

622

623

624

625

626

produced under oxidative stress in chloroplasts [80], in addition to protecting dark respiration and supporting plant growth during the night [81].

In conclusion, our findings suggest that transient seasons (spring and fall) induce the most pronounced chloroplast proteome changes over the year. Out of the 431 proteins isolated in the chloroplast proteome, 41 showed significant abundance changes in different seasons. We also found distinct patterns of protein abundance among the seasons and were able to pinpoint the most abundant proteins in both the dry and wet periods of the year.

\section{The importance of studying chloroplasts metabolic changes}

Chloroplast biogenesis starts with proplastids that areexposed to light and then transformed into mature chloroplasts, whichdifferentiate from gerontoplasts during senescence. Leaf senescence can be triggered by both external and internal factors. Internal factors include age, reproductive growth, redox metabolism, and hormone levels [82-84]. Leaf premature senescence can cause productivity losses due to lower assimilatory capacity [85]. Investigating the complex molecular network behind the developmental processes is essential for understanding the continual transition of functional and regulatory metabolic pathways occurring multiple times throughout the perennials plants lifespan. It is also quite 
627 relevant for agriculture because [86-87] it may open new possibilities to

628 increase crop yield and establish strategies to maximize biomass 629 production.

630 An inter-organellar transcriptomic analysis of leaf senescence in 631 Arabidopsis indicated that the chloroplast transcriptome exhibited the most 632 pronounced changes throughout the plant lifespan [88]. These findings 633 indicate that plastid compartment could be an important target to plant 634 breeding programs that intend to delay leaf senescence and maximize 635 biomass production. Regarding chloroplast metabolism, a large number of 636 differentially expressed transcripts were identified in mature to senescence 637 stages, and the biological processes associated with biogenesis at the growth to maturation stage showed higher expression, suggesting robust 639 transcriptional coordination during early leaf development and more 640 dynamic biochemical transitions during the senescence process [88]. At the 641 protein level, we also observed higher abundance in biogenesis processes in 642 young leaf tissue;in contrast, we detected a larger number of differential 643 abundance proteins for the young stage rather than in mature tissues. This 644 indicates that protein-level dynamics diverges from transcriptome 645 dynamics. The plants also presented a strong translational coordination 646 during early leaf development, and such biochemical networks seem more active during early stages. 
649 due to changing environmental conditions. Perennial plants have been

650 described to be strongly affected by seasonally varying availability of 651 nutrients, water, light, and temperatures [37, 38]. Seasonal climate 652 variations can drive plant growth and development, favoring a metabolic 653 adaptation of the life cycle with changes in the environment [36]. the most pronounced chloroplast proteome changes over the year in Eucalyptus grandis cultivated in tropical climate. For the fall, we 657 foundhigher abundance of proteins related to epigenetic events that are 658 very sensitive to external environment changes. Such epigenetic mechanisms are among the factors that help plants adapt to different environmental climates [66]. The combination of seasonal proteomics and epigenomics studies in natural environments can be important to reveal seasonal dynamics regulation at each level on plant responses plasticity. Moreover, agrometeorological data revealed extremely dry autumn and winter seasons and mean monthly rainfall of almost $10 \mathrm{~mm}$ over the

667 uptake and reduced water loss, osmotic adjustment, and antioxidant capacity [89]. Eucalyptus species have been reportedto have developed 669 astrategy involving lower photosynthetic activity during dry periods 
670

671 672 changes allows to further investigate and understand the mechanisms behind plants adaptation and assist tree breeding programs.

associated with resource reallocation through major changes in the gene expression of primary metabolism [90]. Identifying these metabolic
674

\section{$675 \quad$ Final Remarks \\ Final Remarks} the wet seasons.

Investigation of Eucalyptus grandis chloroplast proteome provided a comprehensive resource for understanding different processes underlying age-dependent and seasonal variation in an organellar level. Our chloroplast isolation and enrichment strategies were effective at reducing the number of cross-contaminants and allowed a deep investigation of the changes occurring in the chloroplast proteome throughout leaf development and the seasons of the year. Distinct patterns of protein accumulation were detected in both assays. The Eucalyptus grandis chloroplast proteome seems prone to catabolic and redox processes as leaves age, while the accumulation of proteins involved in biosynthetic processes are downregulated. Most pronounced proteome changes occurred in the transient seasons of the year with a clear proteome bias towards photosynthesis over

A deeper understanding on age-associated biological networks is important fordeveloping strategies to maximize the biomass production. 
691

692

693

694

695

696

697

698

699

700

701

702

703

704

705

706

707

708

709

710

711

712

713

714

715

716

717

718

719

720

721

722

723

Furthermore, analyzing seasonal dynamics unravels the molecular mechanisms underlying metabolism plasticity and plant adaptation in spatiotemporal networks.

\section{References}

1. Miflin B, Lea, P. Amino acid metabolism. Annu. Rev. Plant Biol. 1977; (28):299-29.

2. Ravanel S, Gakière B, Job D, Douce R. The specific features of methionine biosynthesis and metabolism in plants. Proc. Natl. Acad. Sci. 1998; 95(13):7805-12.

3. Hesse H, Hoefgen R. Molecular aspects of methionine biosynthesis. Trends Plant Sci. 2003;(8):259-62.

4. Kamal AHM, Cho K, Choi JS, Bae KH, Komatsu S, Uozumi N, Woo SH. The wheat chloroplastic proteome. J Proteomics. 2013; (93):326-42.

5. Van Wijk KJ. Plastid proteomics. Plant Physiol Biochem. 2004; 42 (12):963-77.

6. Keegstra K, Cline K. Protein import and routing systems of chloroplasts. Plant cell. 1999; 11(4):557-70.

7. Rossig C, Reinbothe C, Gray J, Valdes O, Von Wettstein D, Reinbothe $\mathrm{S}$. Three proteins mediate import of transit sequence-less precursors into the inner envelope of chloroplasts in Arabidopsis thaliana. Proc. Natl. Acad. Sci. USA. 2013; 110:19962-67.

8. Daniell H, Lin CS, Yu M, Chang WJ. Chloroplast genomes: diversity, evolution, and applications in genetic engineering. Genome biol. 2016; 17(1):134.

9. Myburg AA, Grattapaglia D, Tuskan GA, Hellsten U, Hayes RD, Grimwood J, et al. The genome of Eucalyptus grandis. Nature. 2014; 510(7505):356-62.

10.Pinard D, Myburg AA, Mizrachi E. The plastid and mitochondrial genomes of Eucalyptus grandis. BMC Genomics. 2019;20:132.

11.Taylor NL, Tan YF, Jacoby RP, Millar AH. Abiotic environmental stress induced changes in the Arabidopsis thaliana chloroplast, 
mitochondria and peroxisome proteomes. J Proteomics. 2009;72:367-78.

12. Tamburino R, Vitale M, Ruggiero A, Sassi M, Sannino L, Arena S, et al. Chloroplast proteome response to drought stress and recovery in tomato (Solanum lycopersicum L.). BMC Plant Biol. 2017;17(1):40.

13.Chang L, Wang L, Peng C, Tong Z, Wang D, Ding G, et al. The chloroplast proteome response to drought stress in cassava leaves. Plant Physiol Biochem. 2019;142:351-62.

14.Megias E, Do Carmo LST, Nicolini C, Silva LP, Blawid R, Nagata T, Mehta A. Chloroplast Proteome of Nicotiana benthamiana Infected by Tomato Blistering Mosaic Virus. Protein J. 2018;37(3):290-99.

15.Zhu D, Luo F, Zou R, Liu J, Yan Y. Integrated physiological and chloroplast proteome analysis of wheat seedling leaves under salt and osmotic stresses. J Proteomics. 2021;234:104097.

16.Herrmann HA, Dyson BC, Miller MAE, Schwartz JM, Johnson GN. Metabolic flux from the chloroplast provides signals controlling photosynthetic acclimation to cold in Arabidopsis thaliana. Plant Cell Environ. 2021; 44(1):171-85.

17.Lande NV, Barua P, Gayen D, Kumar S, Varshney S, Sengupta S, Chakraborty S, Chakraborty N. Dehydration-induced alterations in chloroplast proteome and reprogramming of cellular metabolism in developing chickpea delineate interrelated adaptive responses. Plant Physiol Biochem. 2020a;146:337-48.

18. Watson SJ, Sowden RG, Jarvis P. Abiotic stress-induced chloroplast proteome remodelling: a mechanistic overview. J Exp Bot. 2018;69 (11):2773-81.

19.Xiong E, Li Z, Zhang C, Zhang J, Liu Y, Peng T, Chen Z, Zhao Q. A study of leaf-senescence genes in rice based on a combination of genomics, proteomics and bioinformatics. Brief Bioinform. 2021;22 (4):1-35.

20.Pipitone R, Eicke S, Pfister B, Glauser G, Falconet D, Uwizeye C, et al. A multifaceted analysis reveals two distinct phases of chloroplast biogenesis during de-etiolation in Arabidopsis. eLife. eLife Sciences Publication. 2021; 10 . 
21.Huokko T, Ni T, Dykes GF, Simpson DM, Brownridge P, Conradi FD, et al. Probing the biogenesis pathway and dynamics of thylakoid membranes. Nat Commun. 2021; 12 (1):3475.

22. Mielke K, Wagner R, Mishra LS, Demir F, Perrar A, Huesgen PF, Funk C. Abundance of metalloprotease FtsH12 modulates chloroplast development in Arabidopsis thaliana. J Exp Bot. 2021;72(9):3455-73.

23.Flannery SE, Hepworth C, Wood WHJ, Pastorelli F, Hunter CN, Dickman MJ, et al. Developmental acclimation of the thylakoid proteome to light intensity in Arabidopsis. Plant J.2021;105 (1):22344.

24. Bouchnak I, Brugière S, Moyet L, Le Gall S, Salvi D, Kuntz M, et al. Unraveling Hidden Components of the Chloroplast Envelope Proteome: Opportunities and Limits of Better MS Sensitivity. Mol Cell Proteomics. 2019;18 (7):1285-06.

25.Lande NV, Barua P, Gayen D, Kumar S, Chakraborty S, Chakraborty N. Proteomic dissection of the chloroplast: Moving beyond photosynthesis. J Proteomics.2020b;212:103542.

26. Bayer RG, Stael S, Teige M. Chloroplast Isolation and Enrichment of Low-Abundance Proteins by Affinity Chromatography for Identification in Complex Proteomes. Methods Mol Biol. 2021;2261:535-47.

27.Biswal B, Pandey J. Development of Chloroplast Biogenesis, Senescence, and Regulations. Handbook of photosynthesis. Third edition. CRC press; 2016.

28. Thomas H. Senescence, aging and death of the whole plant. New Phytol. 2013;197: 696-11.

29. Rottet S, Besagni C, Kessler F. The role of plastoglobules in thylakoid lipid remodeling during plant development. Biochim Biophys Acta Bioenerg. 2015;1847(9):889-99.

30.Andriankaja M, Dhondt S, De Bodt S, Vanhaeren H, Coppens F, De Milde L, et al. Exit from proliferation during leaf development in Arabidopsis thaliana: a not-so-gradual process. Dev Cell. 2012;22: 64-78.

31.Thatcher SR, Burd S, Wright C, Lers A, Green PJ. Differential expression of miRNAs and their target genes in senescing leaves and 
siliques: insights from deep sequencing of small RNAs and cleaved target RNAs. Plant Cell Environ. 2015; 38:188-200.

32. Biswal B, Biswal UC, Raval MK. Chloroplast biogenesis: From proplastid to gerontoplast. Dordrecht: Kluwer Academic Publishers; 2003.

33.Xue ZC, Gao HY, Zhao SJ. Effects of cadmium on the photosynthetic activity in mature and young leaves of soybean plants. Environ. Sci. Pollut. Res. 2014;(21):4656-64. and increased temperature induce different strategies for competent photosynthesis in young and mature fig leaves. S. Afr. J. Bot. 2016;(103):25-31.

35.Guo Y, Gan SS. Translational researches on leaf senescence for enhancing plant productivity and quality. J Exp Bot. 2014;65(14):3901-13.

36.Donohue K. Why ontogeny matters during adaptation: developmental niche construction and pleiotorpy across the life cycle in Arabidopsis thaliana. Evolution. 2014;68:32-47.

37.Kimberley MO, Richardson B. Importance of seasonal growth patterns in modelling interactions between radiata pine and some common weed species, Can J For Res. 2004;(34):184-94.

38. Nazarova GG. Effects of seasonal, ontogenetic, and genetic factors on lifespan of male and female progeny of Arvicola amphibious. Front Genet. 2013;(4):100.

39.Dillen SY, Rood RSB. Ceulemans Growth and physiology. Genetics and Genomics of Populus. 2010;8:39-66.

40. Van Goethem D, Potters G, De Smedt S, Gu L, Samson R. Seasonal, diurnal and vertical variation in photosynthetic parameters in Phyllostachys humilis bamboo plants. Photosynth Res. 2014;120:331-46.

41. Yang HB, An SQ, Sun OJ, Shi ZM, She XS, Sun QY, Liu SR. Seasonal variation and correlation with environmental factors of photosynthesis and water use efficiency of Juglans regia and Ziziphus jujuba. J Integr Plant Biol. 2008;50:210-22.

42. Alvares CA, Stape JL, Sentelhas PC, Gonçalves, JLM, Sparovek, G. Koppen's climate classification map for Brazil. Meteorologische Zeitschrift. 2013;22(6):711-28. 
43.A. Shevchenko A, Tomas H, Havlis J, Olsen JV, Mann M. In-gel digestion for mass spectrometric characterization of proteins and proteomes. Nature Protocols.2007; 1(6):2856-60.

44. Tyanova S, Temu T, Cox J. The MaxQuant computational platform for mass spectrometry-based shotgun proteomics. Nat Protocols. 2016a;(11):2301-19.

45.Paoletti AC, Parmely TJ, Tomomori-Sato C, Sato S, Zhu D, Conaway, RC, et al. Quantitative proteomic analysis of distinct mammalian Mediator complexes using normalized spectral abundance factors. Proc Natl Acad Sci U S A. 2006;103(50):1892833.

46. Tyanova S, Temu T, Sinitcyn P, Carlson A, Hein MY, Geiger T, et al. The Perseus computational platform for comprehensive analysis of (prote)omics data. Nat Methods. 2016b;13:731-40.

47.Götz S, Garcia-Gomez JM, Terol J, Williams TD, Nagaraj SH, Nueda MJ, et al. High throughput functional annotation and data mining with the blast2go suite. Nucl. Acids Res. 2008;36:3420-35.

48. Emanuelsson O, Nielsen $\mathrm{H}$, von Heijne G. ChloroP, a neural network-based method for predicting chloroplast transit peptides and their cleavage sites. Protein Sci. 1999;8(5):978-84.

49.Small I, Peeters N, Legeai F, Lurin C. Predotar: A tool for rapidly screening proteomes for N-terminal targeting sequences. Proteomics. 2004 Jun;4(6):1581-90.

50.Sun Q, Zybailov B, Majeran W, Friso G, Olinares PD, van Wijk KJ. PPDB, the Plant Proteomics Database at Cornell. Nucleic Acids Res. 2009 Jan;37(Database issue):D969-74.

51.Salvi D, Bournais S, Moyet L, Bouchnak I, Kuntz M, Bruley C, Rolland N. AT_CHLORO: The First Step When Looking for Information About Subplastidial Localization of Proteins. Methods Mol Biol. 2018;1829:395-406.

52. Mattiello L, Riaño-Pachón DM, Martins MC, Da Cruz LP, Bassi D, Marchiori PE, et al. Physiological and transcriptional analyses of developmental stages along sugarcane leaf. BMC plant biology, 2015;15(300).

53.Biswal B, Joshi PN, Raval MK, Biswal UC. Photosynthesis, a global sensor of environmental stress in green plants: Stress signaling and adaptation. Curr. Sci. 2011;101:47-56. 
54. Chan KX, Phua SY, Crisp P, Mcquinn R, Pogson BJ. Learning the languages of the chloroplast: retrograde signaling and beyond. Annu Rev Plant Biol. 2016;(67):25-53.

55.Li P, Ponnala L, Gandotra N, Wang L, Si Y, Tausta SL, et al. The developmental dynamics of the maize leaf transcriptome. Nat Genet. 2010;42:1060-67.

56.Zrenner R, Riegler H, Marquard CR, Lange PR, Geserick C, Bartosz $\mathrm{CE}$, et al. A functional analysis of the pyrimidine catabolic pathway in Arabidopsis. New phytologist. 2009;183(1):117-32.

57.Levesque-Tremblay G, Havaux M, Ouellet F. The chloroplastic lipocalin AtCHL prevents lipid peroxidation and protects Arabidopsis against oxidative stress. Plant J. 2009;60(4):691-702.

58. Malnoë A, Schultink A, Shahrasbi S, Rumeau D, Havaux M, Niyogi KK. The Plastid Lipocalin LCNP Is Required for Sustained Photoprotective Energy Dissipation in Arabidopsis. Plant cell. 2018;30(1):196-208.

59.Cheng YC, Fleming GR. Dynamics of light harvesting in photosynthesis. Annu Rev Phys Chem. 2009;60:241-62.

60.Bauerle WL, R. Oren, D. A. Way, S. S. Qian, P. C. Stoy, P. E. Thornton. Pattern of photosynthetic capacity and the implications for carbon cycling. Proc Natl Acad Sci USA. 2012;109: 8612-17.

61. Medvigy D, Jeong SJ, Clark KL, Skowronski NS, Schäfer KV. Effects of seasonal variation of photosynthetic capacity on the carbon fluxes of a temperate deciduous forest. Journal of Geophysical Research - Biogeosciences. 2013;118:1703-14.

62.Xu L, Baldocchi DD. Seasonal trends in photosynthetic parameters and stomatal conductance of blue oak (Quercus douglasii) under prolonged summer drought and high temperature. Tree Physiology. 2003;23:865-77.

63. Yang H, Yang X, Zhang Y, Heskel MA, Lu X, Munger JW, Sun S, Tang J. Chlorophyll fluorescence tracks seasonal variations of photosynthesis from leaf to canopy in a temperate forest. Glob Change Biol. 2017;23:2874-86.

64. Sello S, Meneghesso A, Alboresi A, Baldan B, Morosinotto T. Plant biodiversity and regulation of photosynthesis in the natural environment. Planta. 2019;249:1217-28. 
65.Chang CY, Unda F, Zubilewich A, Mansfield SD, Ensminger I. Sensitivity of cold acclimation to elevated autumn temperature in field-grown Pinus strobus seedlings. Front. Plant Sci.2015;6:165.

66. Baulcombe DC, Dean C. Epigenetic regulation in plant responses to the environment. Cold Spring Harb Perspect Biol. 2014;6(9):a019471.

67.Howe GT, Horvath DP, Dharmawardhana P, Priest HD, Mockler TC, Strauss SH. Extensive transcriptome changes during natural onset and release of vegetative bud dormancy in Populus. Front. Plant Sci. 2015;6:989.

68. Brossa R, Pintó-Marijuan M, Francisco R, López-Carbonell M, Chaves MM, Alegre L. Redox proteomics and physiological responses in Cistus albidus shrubs subjected to long-term summer drought followed by recovery. Planta. 2015;241(4):803-22.

69. Sathish P, Withana N, Biswas M, Bryant C, Templeton K, Al-Wahb $\mathrm{M}$, et al. Transcriptome analysis reveals season-specific rbcS gene expression profiles in diploid perennial ryegrass (Lolium perenne L.). Plant Biotechnol J. 2007;5(1):146-61.

70.Burnett AC, Serbin SP, Lamour J, Anderson J, Davidson KJ, Yang D, Rogers A. Seasonal trends in photosynthesis and leaf traits in scarlet oak, Tree Physiology. 2021; 41(8):1413-24.

71.Liu J, Last RL. MPH1 is a thylakoid membrane protein involved in protecting photosystem II from photodamage in land plants. Plant Signal Behav. 2015;10(10):e1076602.

72.Buhr F, Bakkouri M, Valdez O, Pollmann S, Lebedev N, Reinbothe S, Reinbothe C. Photoprotective role of NADPH: protochlorophyllide oxidoreductase A. Proc Natl Acad Sci USA. 2008;105:12629-34.

73. Heyes DJ, Hunter CN. Making light work of enzyme catalysis: protochlorophyllide oxidoreductase. Trends Biochem Sci. 2005;(30):642-649.

74.Paddock T, Lima D, Mason ME, Apel K, Armstrong GA. Arabidopsis light-dependent protochlorophyllide oxidoreductase A (PORA) is essential for normal plant growth and development. Plant Mol Biol. 2012;78:447-60.

75.Budzinski IGF, Moon DH, Morosini JS, Lindén P, Bragatto J, Moritz $\mathrm{T}$, et al. Integrated analysis of gene expression from carbon 
metabolism, proteome and metabolome, reveals altered primary metabolism in Eucalyptus grandis bark, in response to seasonal variation. BMC Plant Biol. 2016;16:149.

76.Jungsukcharoen J, Chokchaichamnankit D, Srisomsap C, Cherdshewasart W, Sangvanich P. Proteome analysis of Pueraria mirifica tubers collected in different seasons. Biosci Biotechnol Biochem. 2016; 80(6):1070-108.

77.Ding L, Hofius D, Hajirezaei MR, Fernie AR, Börnke F, Sonnewald U. Functional analysis of the essential bifunctional tobacco enzyme 3-dehydroquinate dehydratase/shikimate dehydrogenase in transgenic tobacco plants. J Exp Bot. 2007; 58(8):2053-67. Milkowski C. Dehydroquinate dehydratase/shikimate dehydrogenases involved in gallate biosynthesis of the aluminumtolerant tree species Eucalyptus camaldulensis. Planta. 2021; 253(3). 79. Mano J, Torii Y, Hayashi S, Takimoto K, Matsui K, Nakamura K, et al. The NADPH: quinone oxidoreductase P1- $\zeta$-crystallin in Arabidopsis catalyzes the $\alpha, \beta$-hydrogenation of 2-alkenals: detoxication of the lipid peroxide-derived reactive aldehydes. Plant Cell Physiol.2002; (43):1445-55.

80. Yamauchi Y, Hasegawa A, Mizutani M, Sugimoto Y. Chloroplastic NADPH-dependent alkenal/one oxidoreductase contributes to the detoxification of reactive carbonyls produced under oxidative stress. FEBS Letters. 2012;586(8):1208-13.

81.Takagi D, Ifuku K, Ikeda K, Inoue KI, Park P, Tamoi M, et al. Suppression of Chloroplastic Alkenal/One Oxidoreductase Represses the Carbon Catabolic Pathway in Arabidopsis Leaves during Night. Plant Physiol. 2016;170(4):2024-39.

82. Mayta ML, Hajirezaei MR, Carrillo N, Lodeyro AF. Leaf Senescence: The Chloroplast Connection Comes of Age. Plants (Basel). 2019 Nov 12;8(11):495.

83.Gan S. Mitotic and post-mitotic senescence in plants. Science's SAGE KE 2003(38), RE7.

84.Jibran R Hunter D Dijkwel P. Hormonal regulation of leaf senescence through integration of developmental and stress signals. Plant Molecular Biology. 2013; 82: 547-61. 
997

998

999

1000

1001

1002

1003

1004

1005

1006

1007

1008

1009

1010

1011

1012

1013

1014

1015

85.Egli DB. Seed-fill duration and yield of grain crops. In: Advances in Agronomy. San Diego: Elsevier Academic Press Inc. 2004; 83:243279 .

86. Gregersen PL, Culetic A, Boschian L, Krupinska K. Plant senescence and crop productivity. Plant Mol. Biol. 2013;82:603-22.

87. Moschen S, Higgins J, Di Rienzo JA, Heinz RA, Paniego N, Fernández $\mathrm{P}$. Network and biosignature analysis for the integration of transcriptomic and metabolomic data to characterize leaf senescence process in sunflower. BMC Bioinform. 2016;17:174.

88. Woo HR, Koo HJ, Kim J, Jeong H, Yang JO, Lee IH, et al. Programming of Plant Leaf Senescence with Temporal and InterOrganellar Coordination of Transcriptome in Arabidopsis, Plant Physiology. 2016;171(1):452-67.

89.Zhang Q. Strategies for developing Green Super Rice. Proc. Natl. Acad. Sci. USA. 2007;104:16402-09.

90.Villar E, Klopp C, Noirot C. et al. RNA-Seq reveals genotypespecific molecular responses to water deficit in Eucalyptus. BMC Genomics. 2011;12: 538.

\section{Supporting information}

S1 Fig. Eucalyptus grandis sampling. Leaf developmental assay, branches were divided into 3 different regions (young, middle, and mature), according to the fluorescence data (FV/FM)and chlorophyll relative quantification (CCI) (A). Proteome seasonal variation assay, forty leaves were collected from the first until the fifth node in all four seasons (Spring, Summer, Fall and Winter) (B).

S2 Fig. Eucalyptus grandis leaf responses. Chlorophyll content index (CCI) (A) and Quantum efficiency of photosystem II (FV/FM) (B). Leaves were isolated from young, middle, and mature regions as described in the Material and Methods section. Different letters indicate significant differences according to Tukey's test $(\mathrm{p}<0.05)$.

S1 Table. Meteorological data recorded at the Sao Paulo State University Forest Nursery during Eucalyptus grandis cultivation. 
S2 Table. Eucalyptus grandis non-redundant protein dataset

1018 S3 Table. Expression profile of the differentially regulated proteins 1019 identified in the Eucalyptus grandis chloroplasts during leaf 1020 development. Proteins were classified according to their abundance 1021 profile: "up-regulated" - proteins with the highest abundance in mature 1022 leaves; "down-regulated" - proteins with the lowest abundance in young 1023 leaves; "undefined" - proteins with undefined profile pattern.

1024

1025 S4 Table. Differentially abundant proteins according to the Tukey's 1026 test $(\mathbf{p}<\mathbf{0 . 0 5})$ in Eucalyptus grandis chloroplasts isolated in different 1027 seasons of the year classified per protein expression pattern. 
A

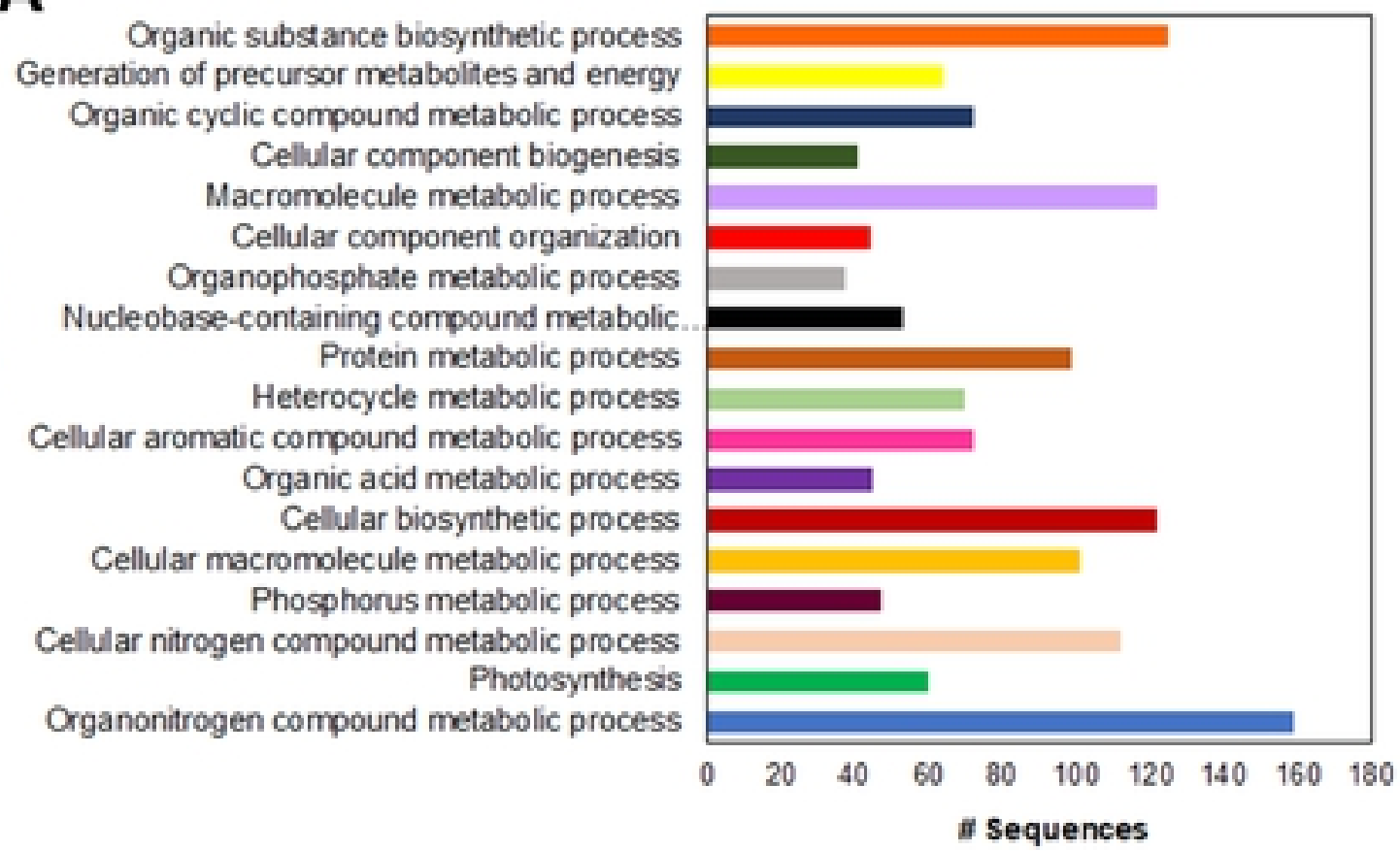

C

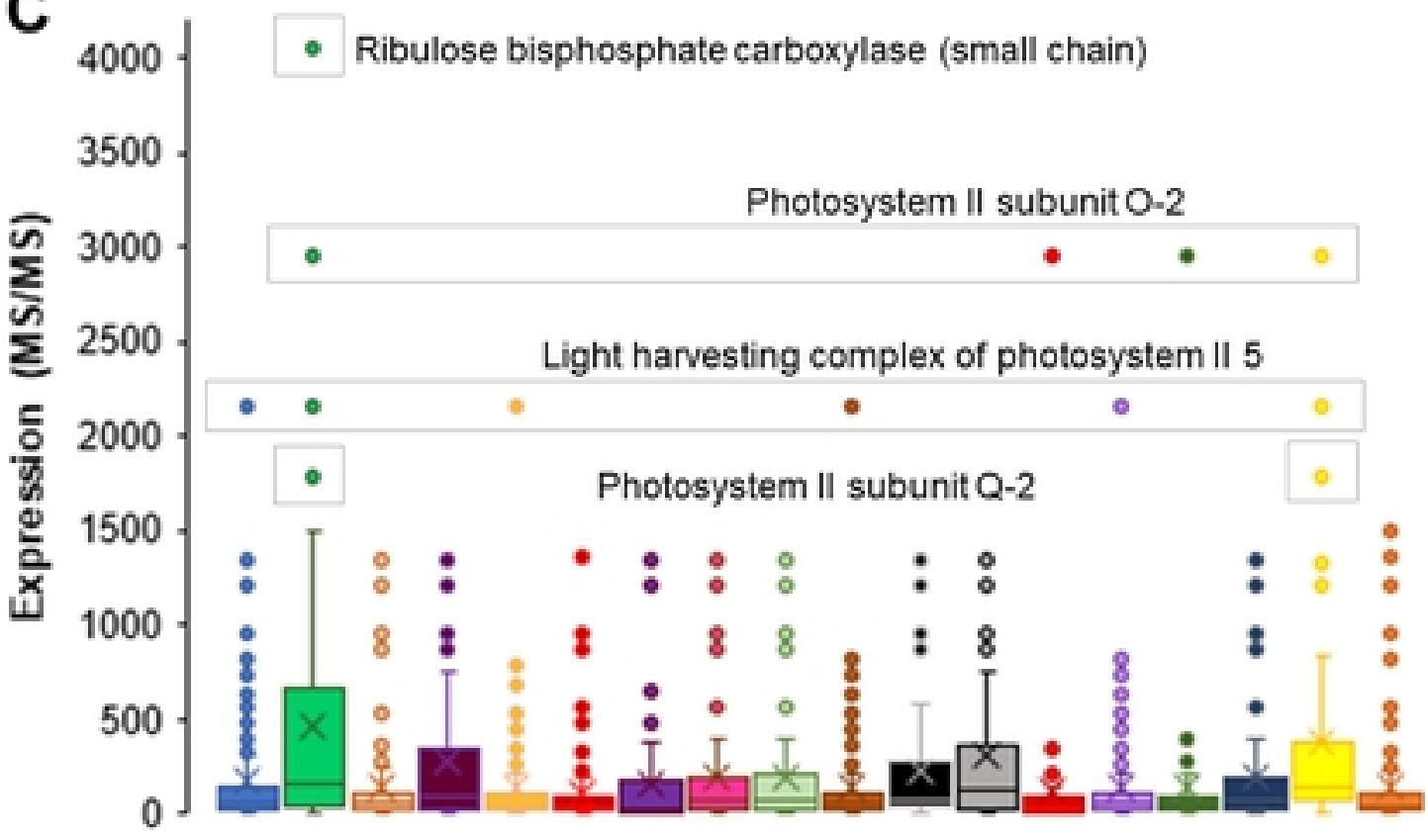

GO Names
B Organic substance biosynthetic

Organonitrogen compound metabolic Generation of precursor metabolites and energy process process

Organic cyclic compound metabolic process$$
5 \%
$$

Cellular component biogenesis $2 \%$

Macromolecule metabolic

$$
\text { process }
$$

Cellular component$$
2 \%
$$

Organophosphate

$$
\text { process }
$$

$4 \%$

Nucleobase-containing compound metabolic process $5 \%$

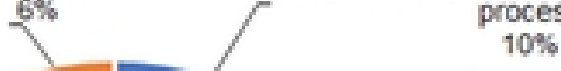

D

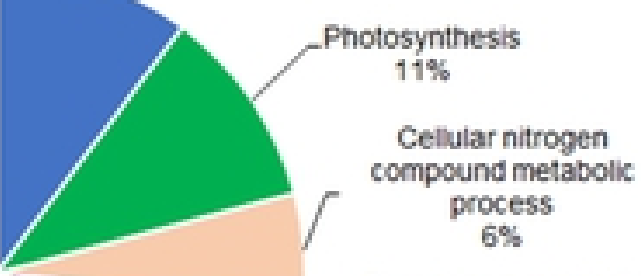

Phosphorus metabolic process

Cellular macromolecule metabolic process $5 \%$

Cellular biosynthetic process

Organic acid metabolic process 3\%

Protein metabolic $]_{\begin{array}{c}\text { Heterocycle } \\ \text { metabolic process }\end{array}}$ Cellular aromatic compound metabolic process

proces:

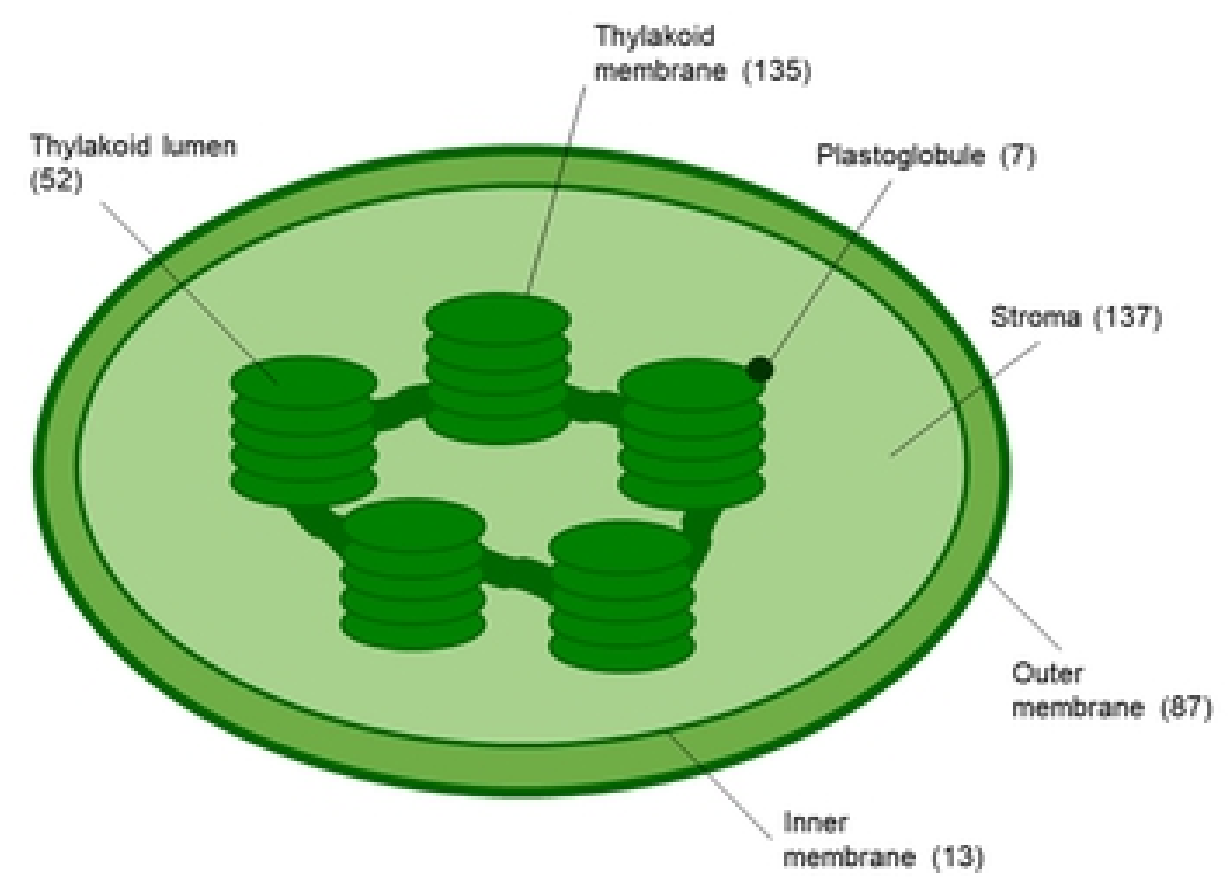

Figure 1 
A

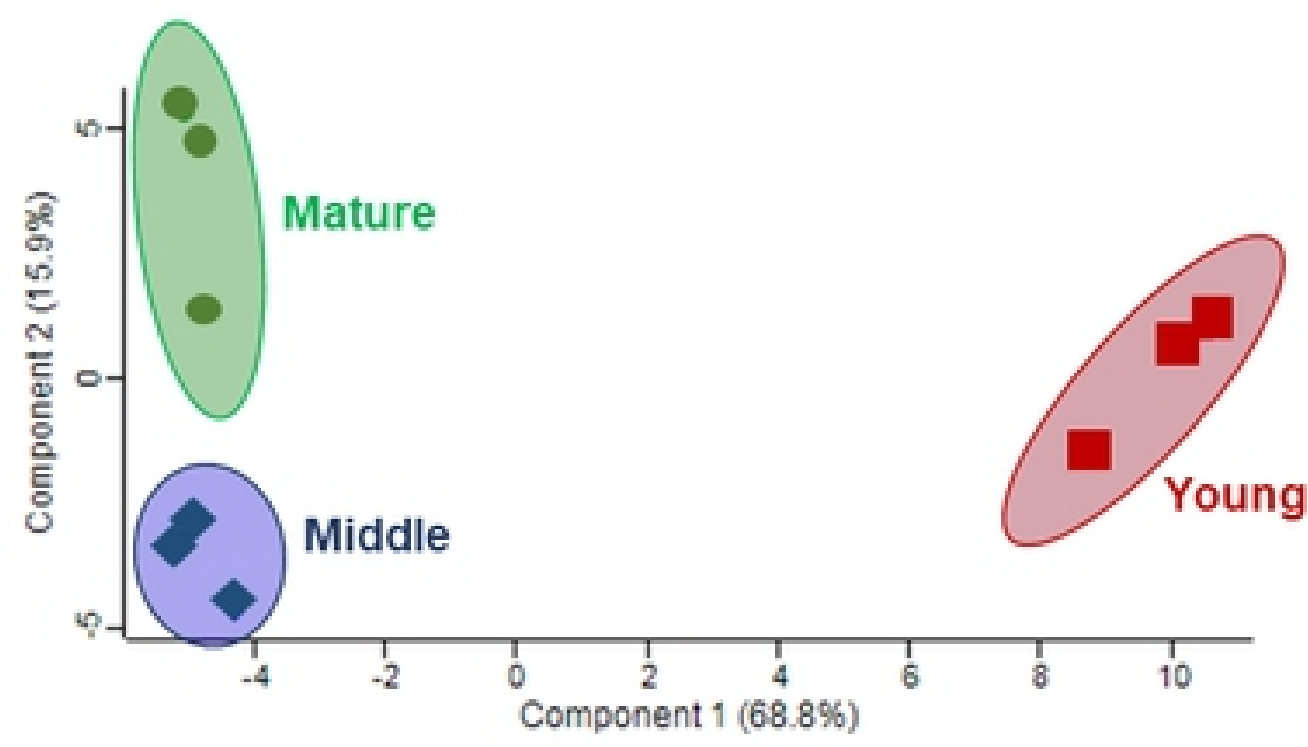

B
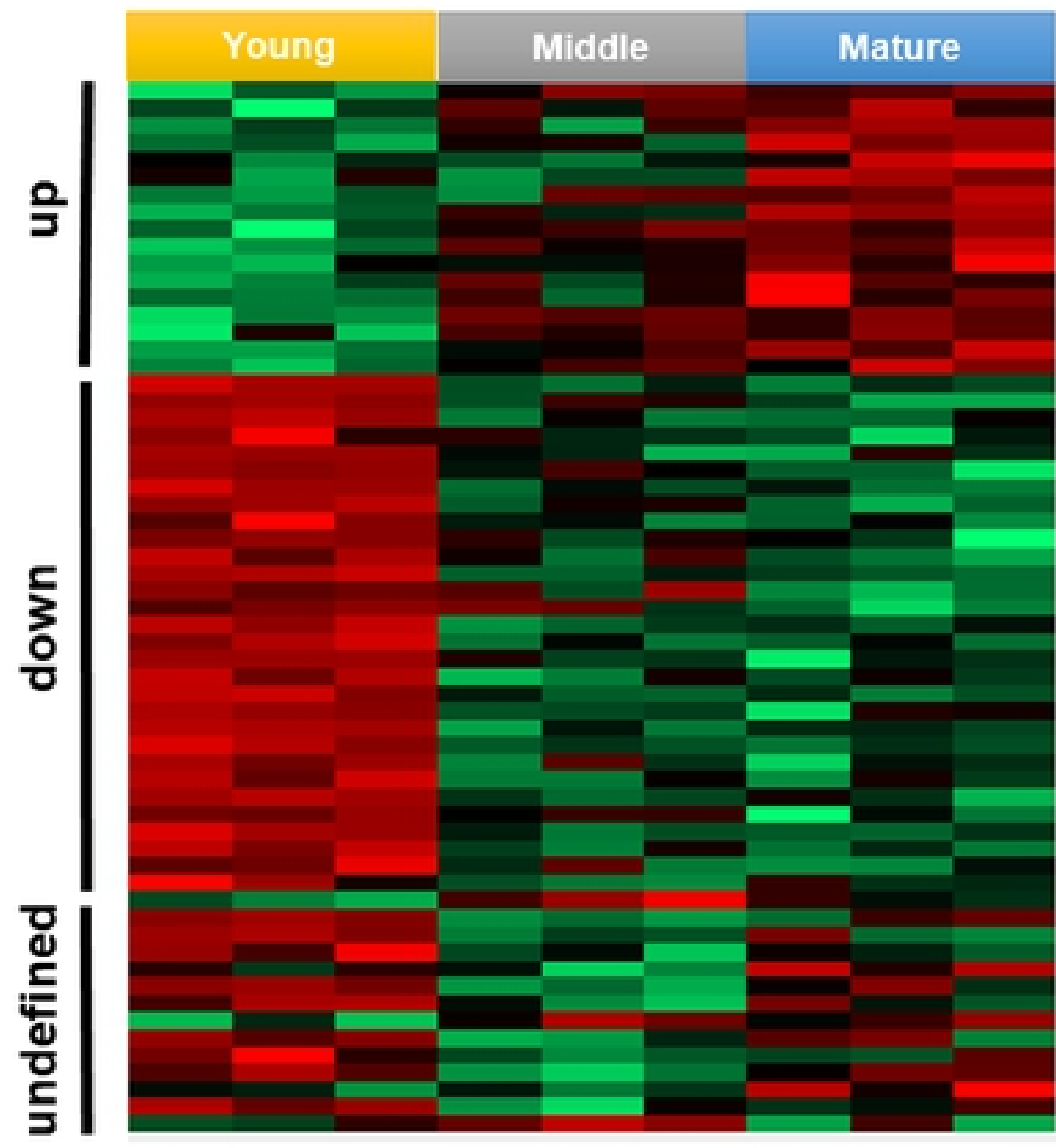

C

\section{Up-regulated}

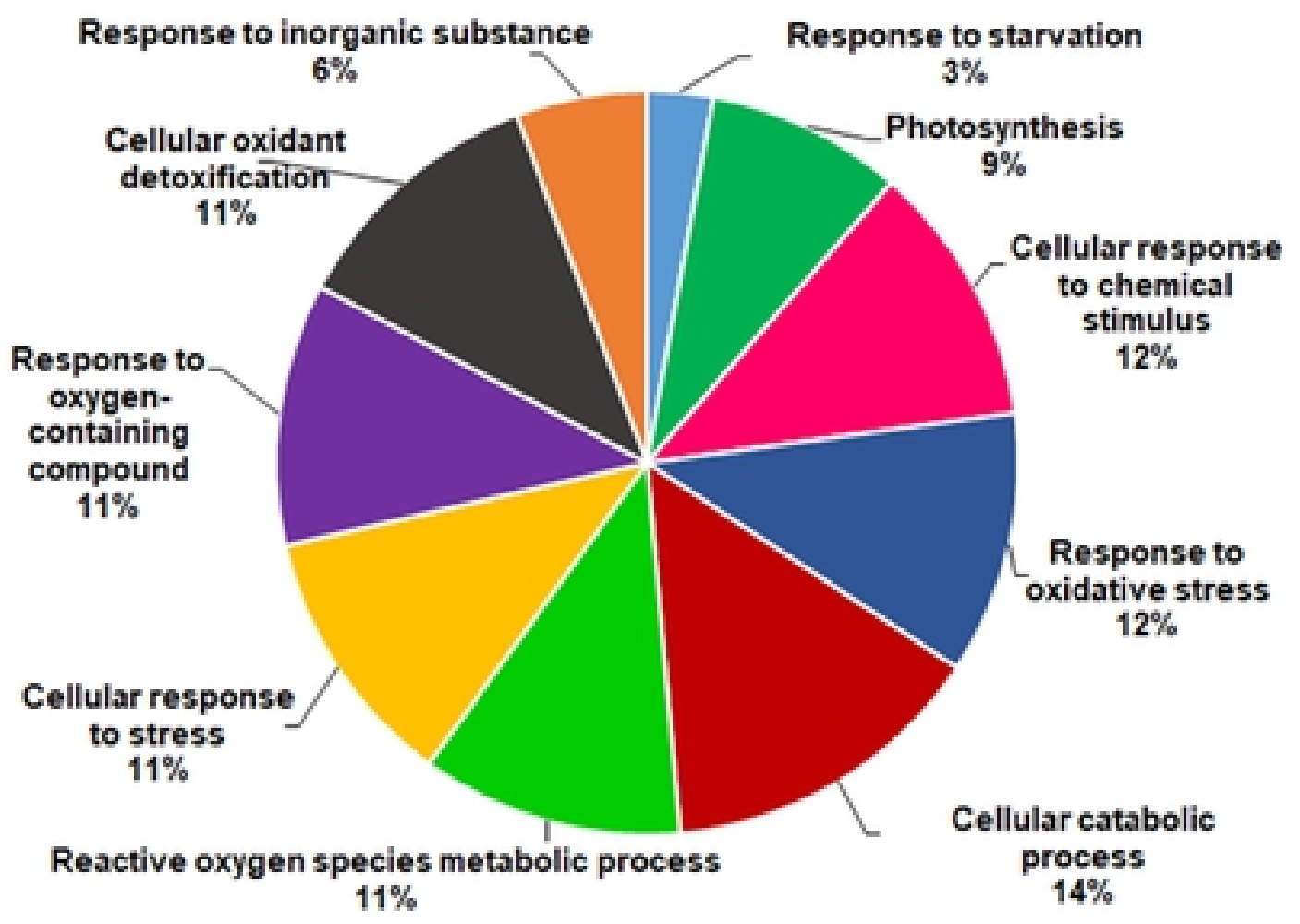

\section{Down-regulated}
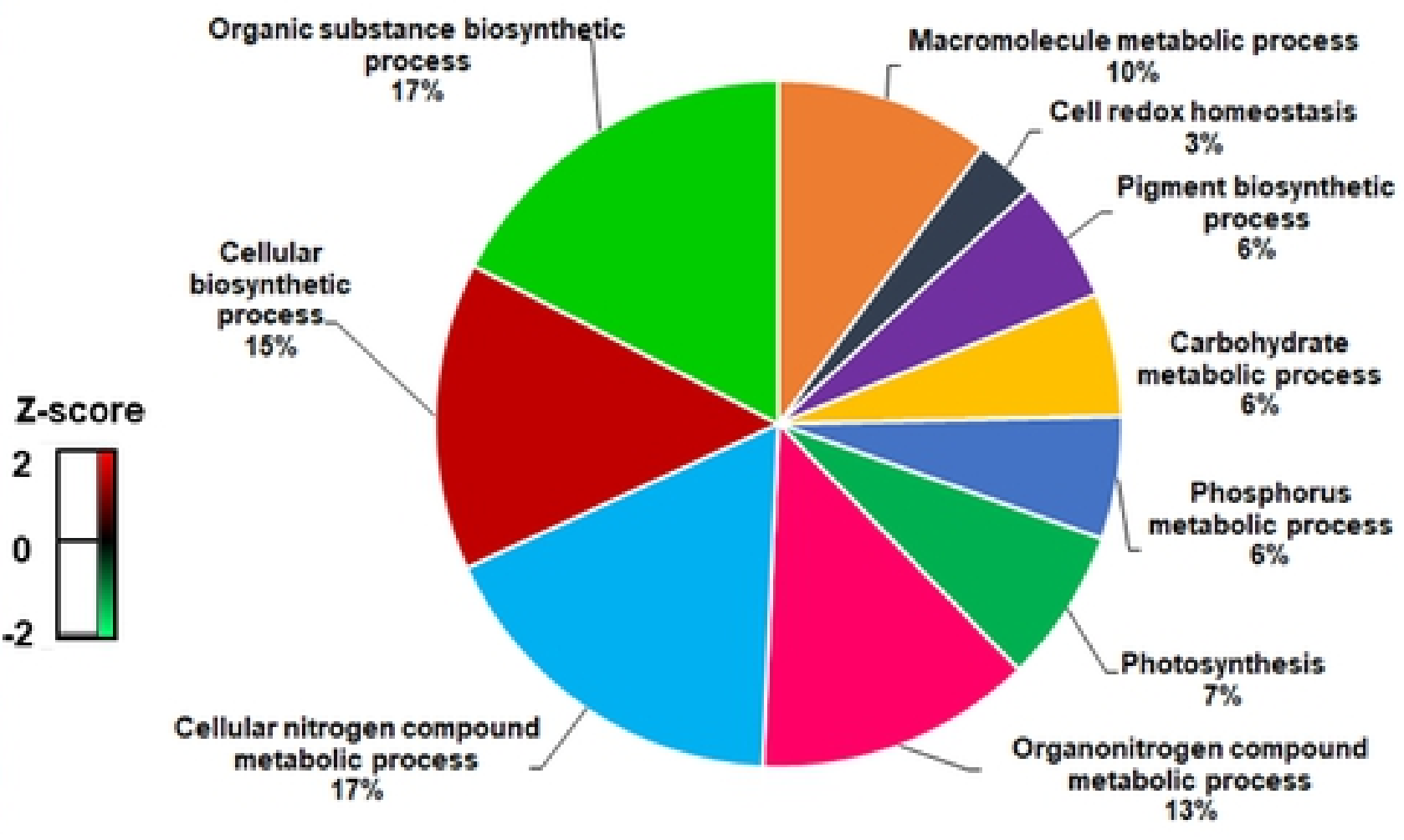

Figure 2 


\section{Early}

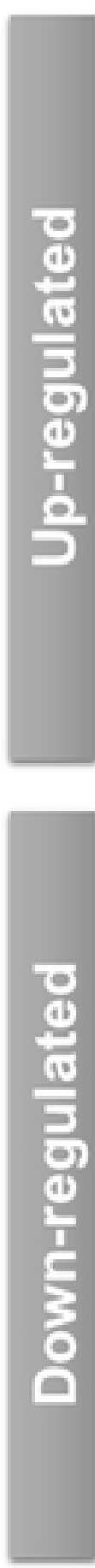

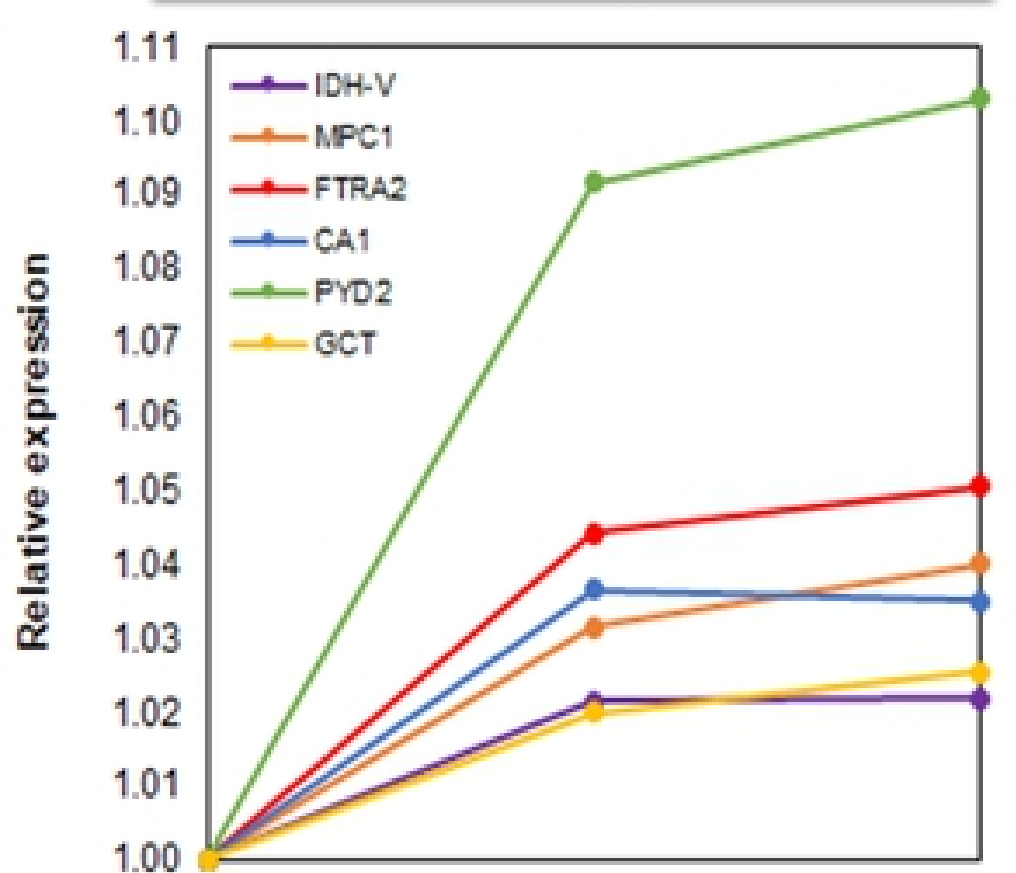

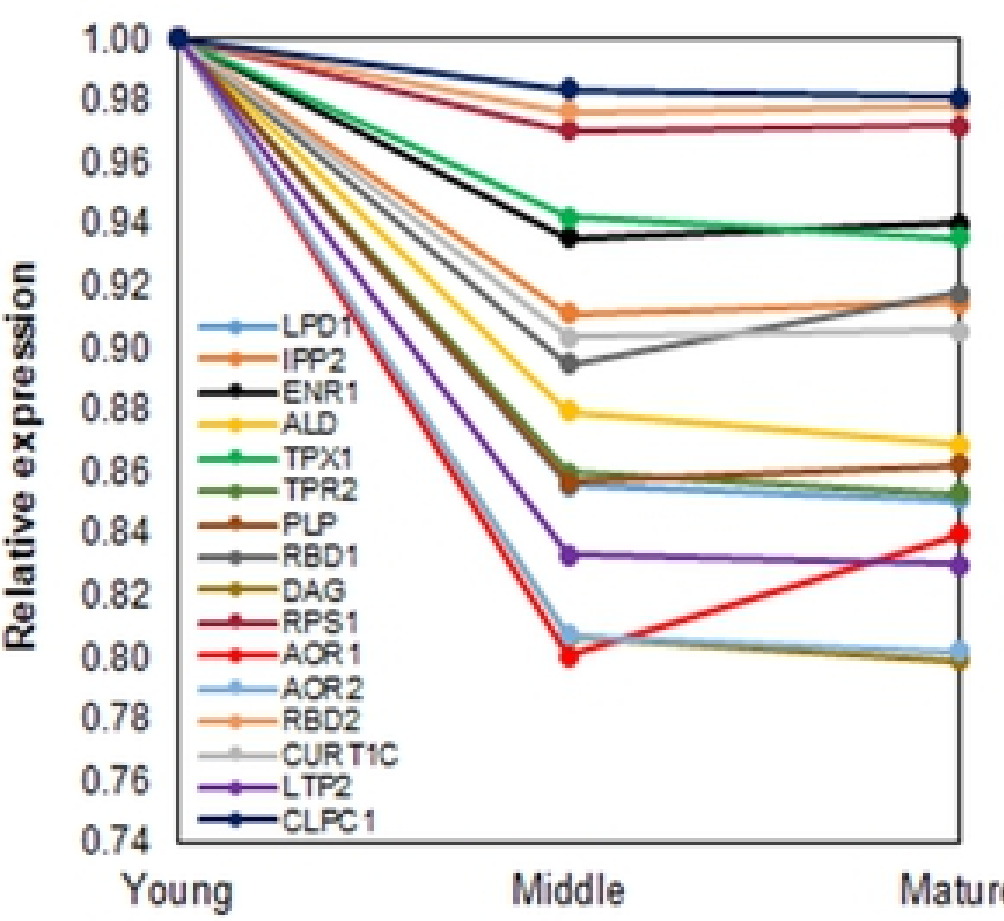

\section{Late}
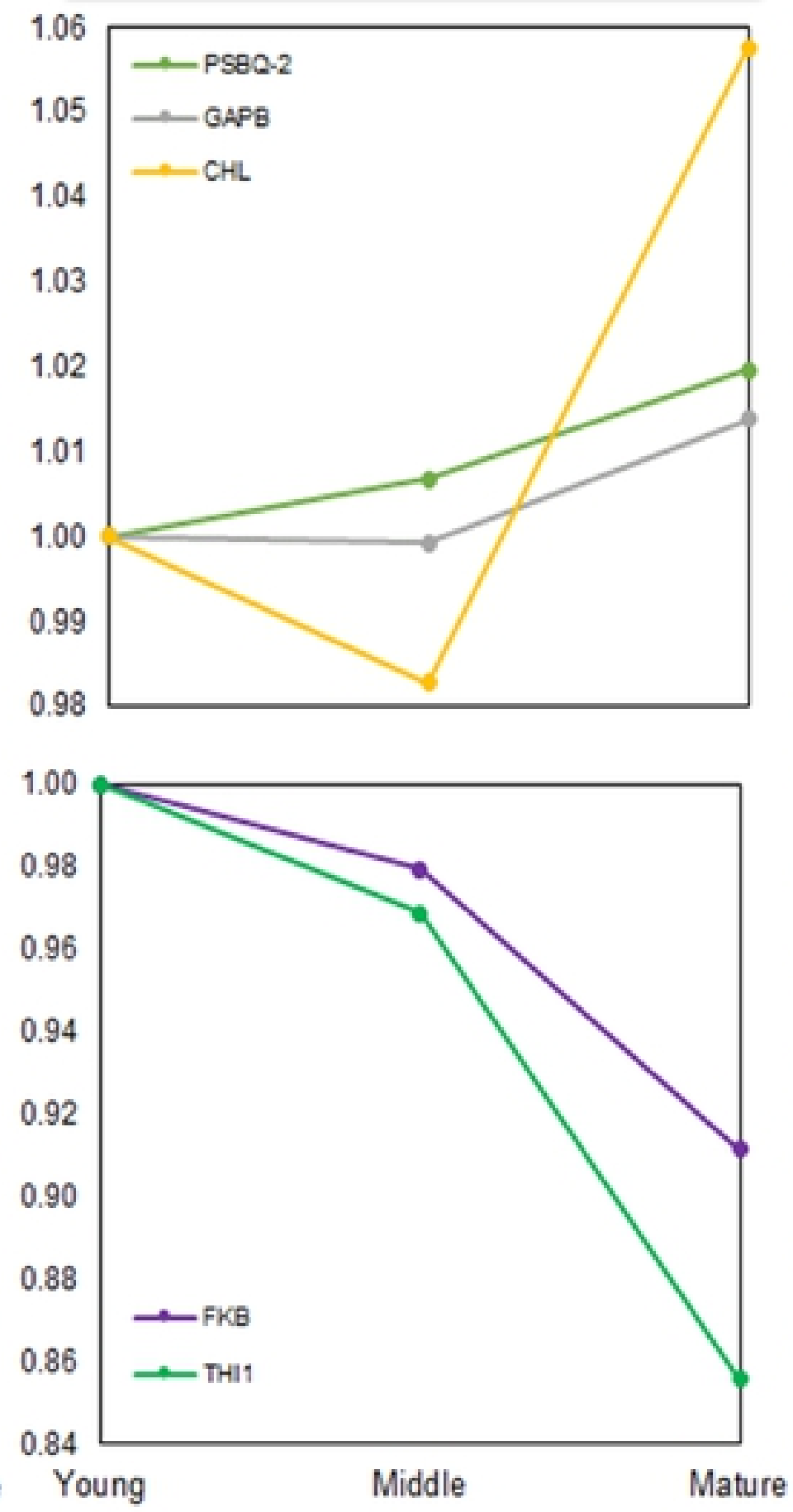

\section{Linear}
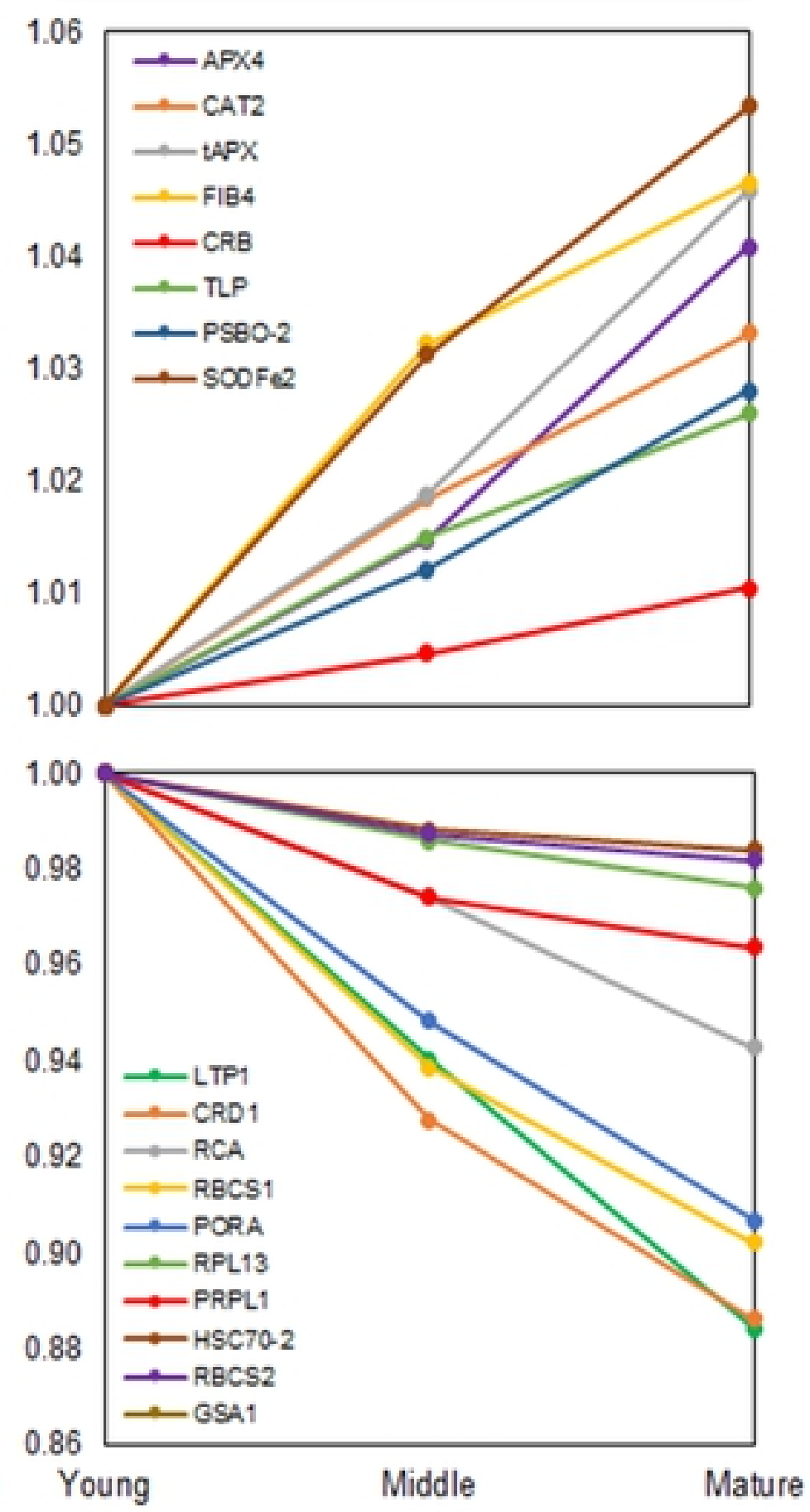

\section{Figure 3}


A

$\square$ Spring

$\square$ Summer

$\square$ Autumn

$\square$ Winter

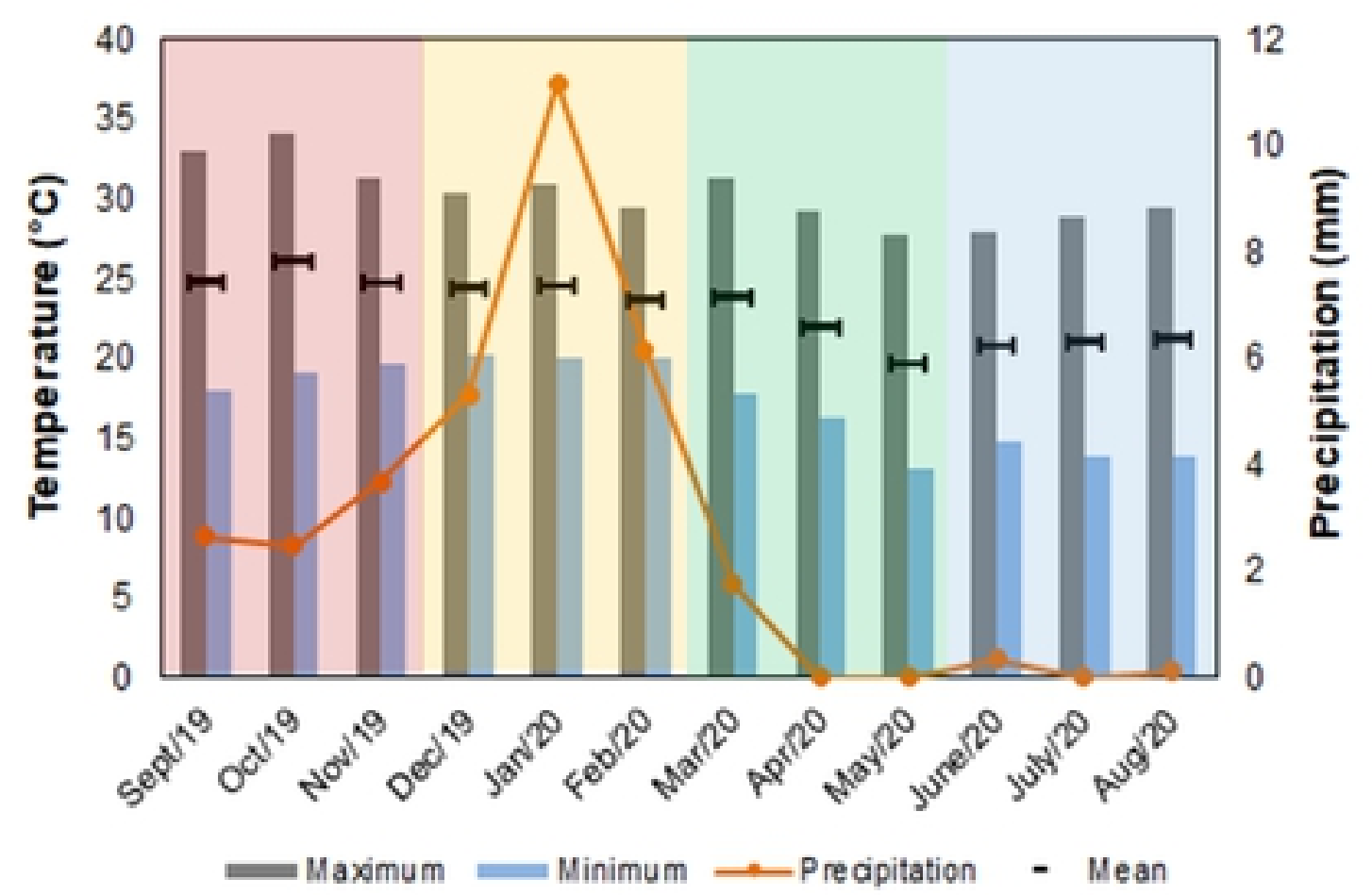

B

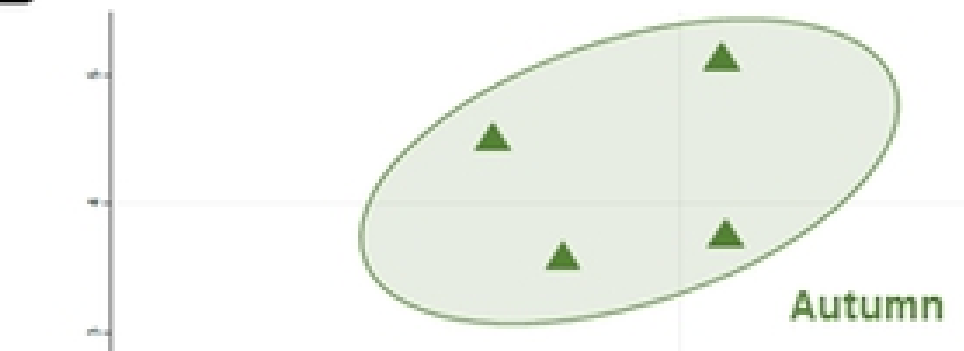

Summer

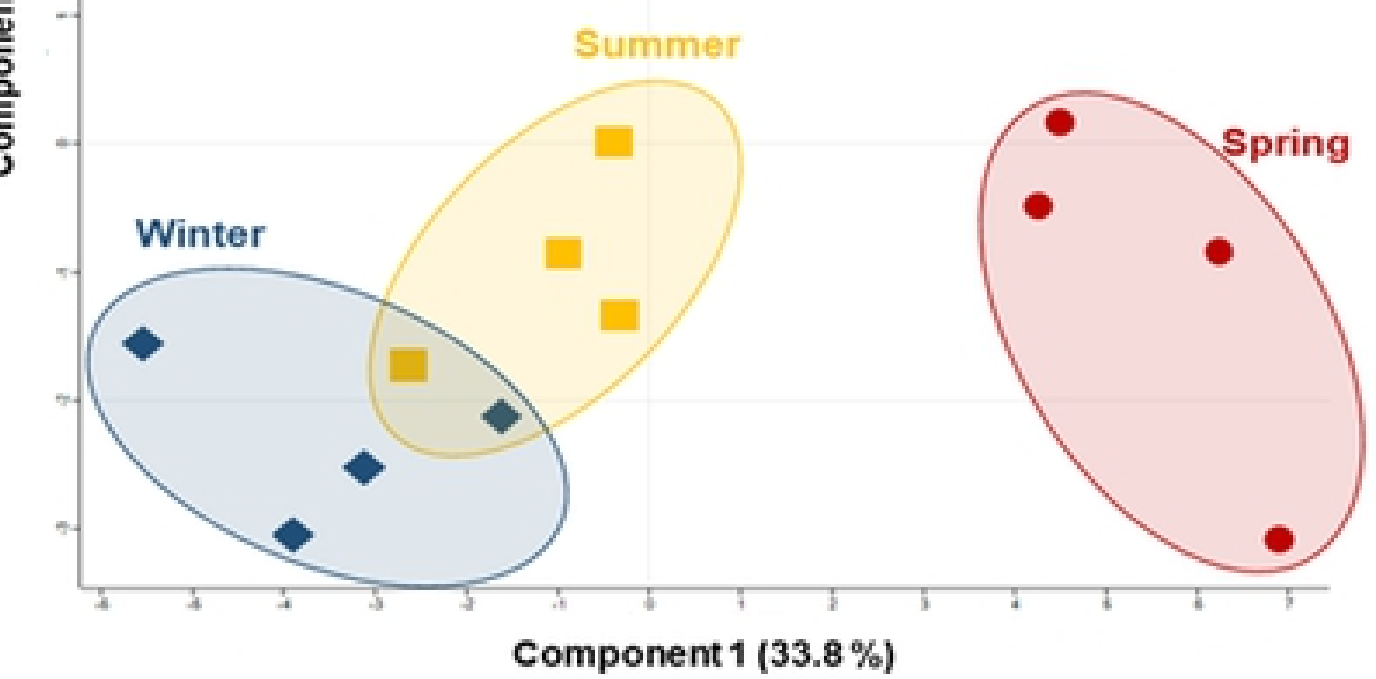

Figure 4 
A

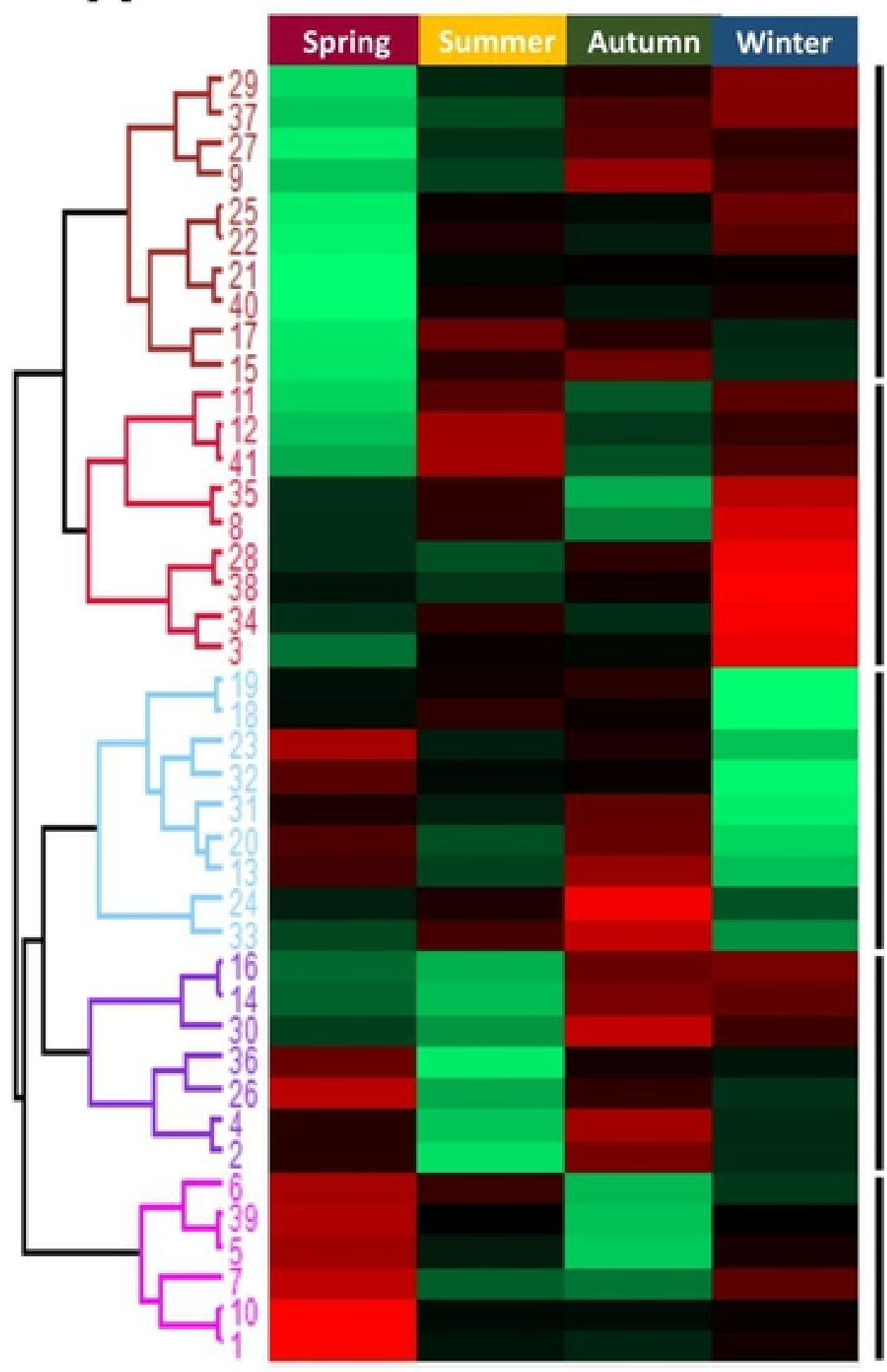

B

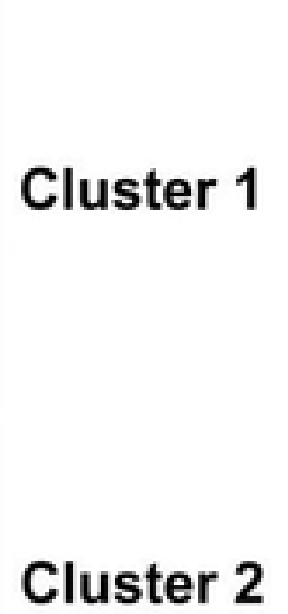

Cluster 3

Cluster 4

Cluster 5
Cluster 1

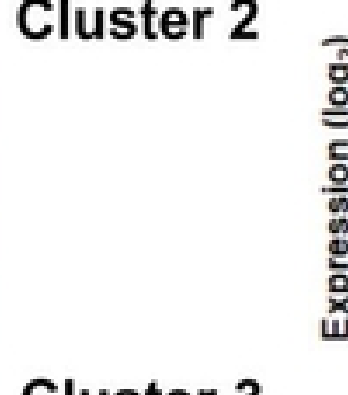

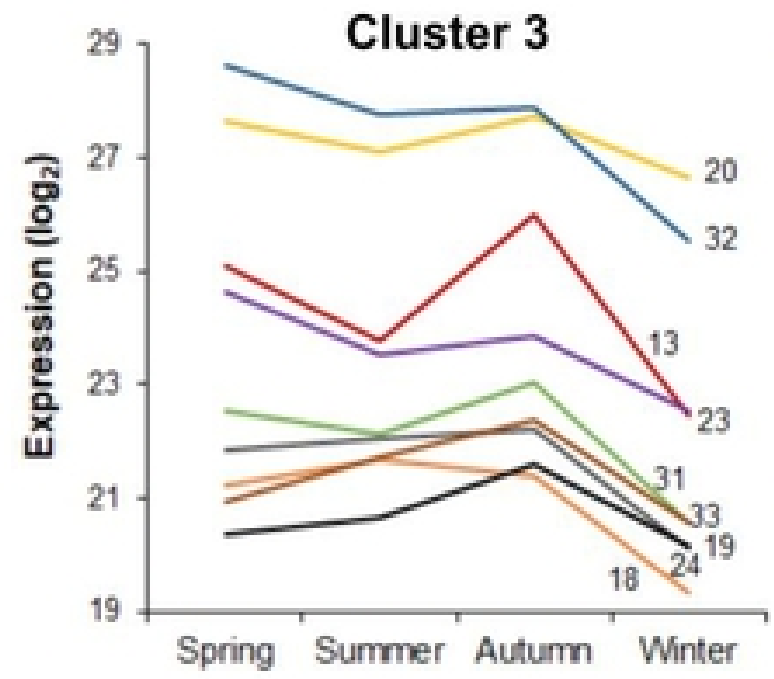

\section{Cluster 2}

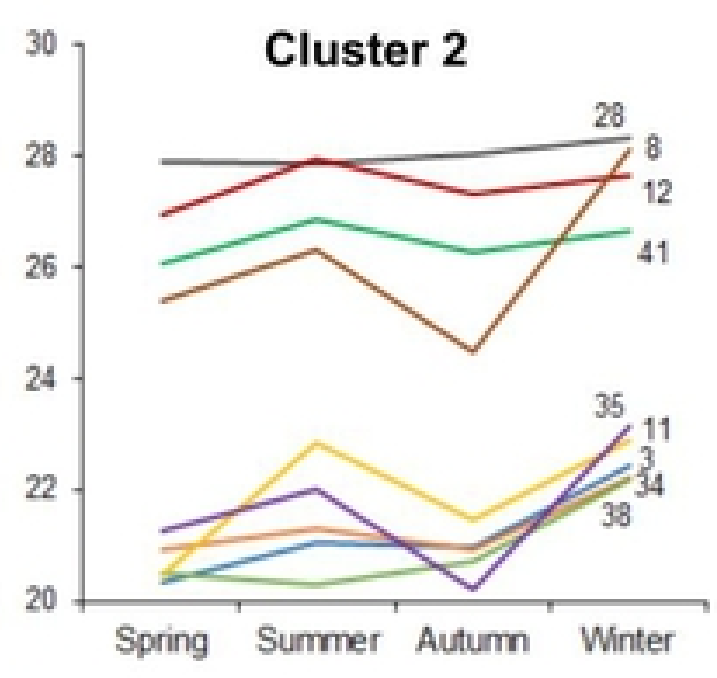

Cluster 4
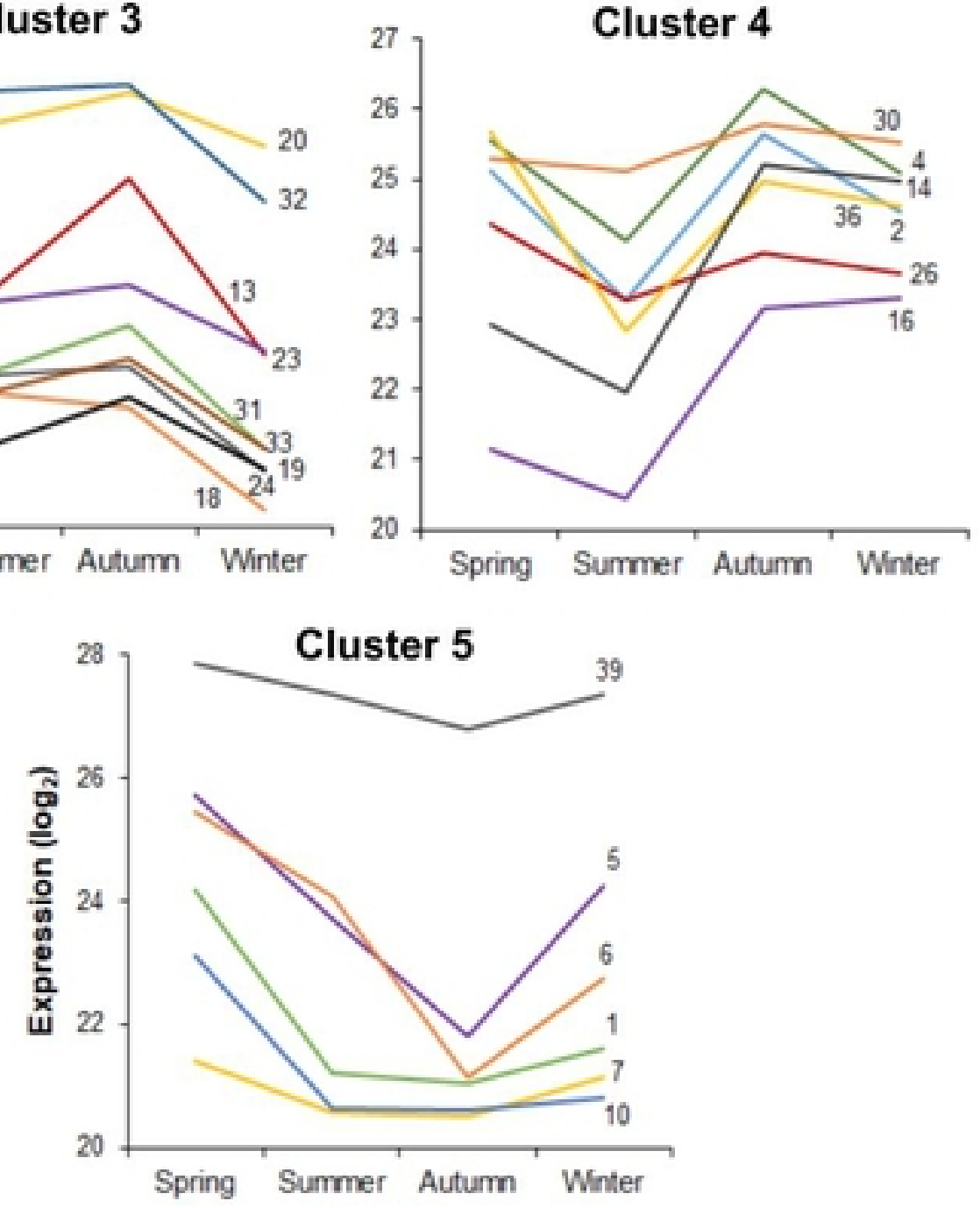

Figure 5 


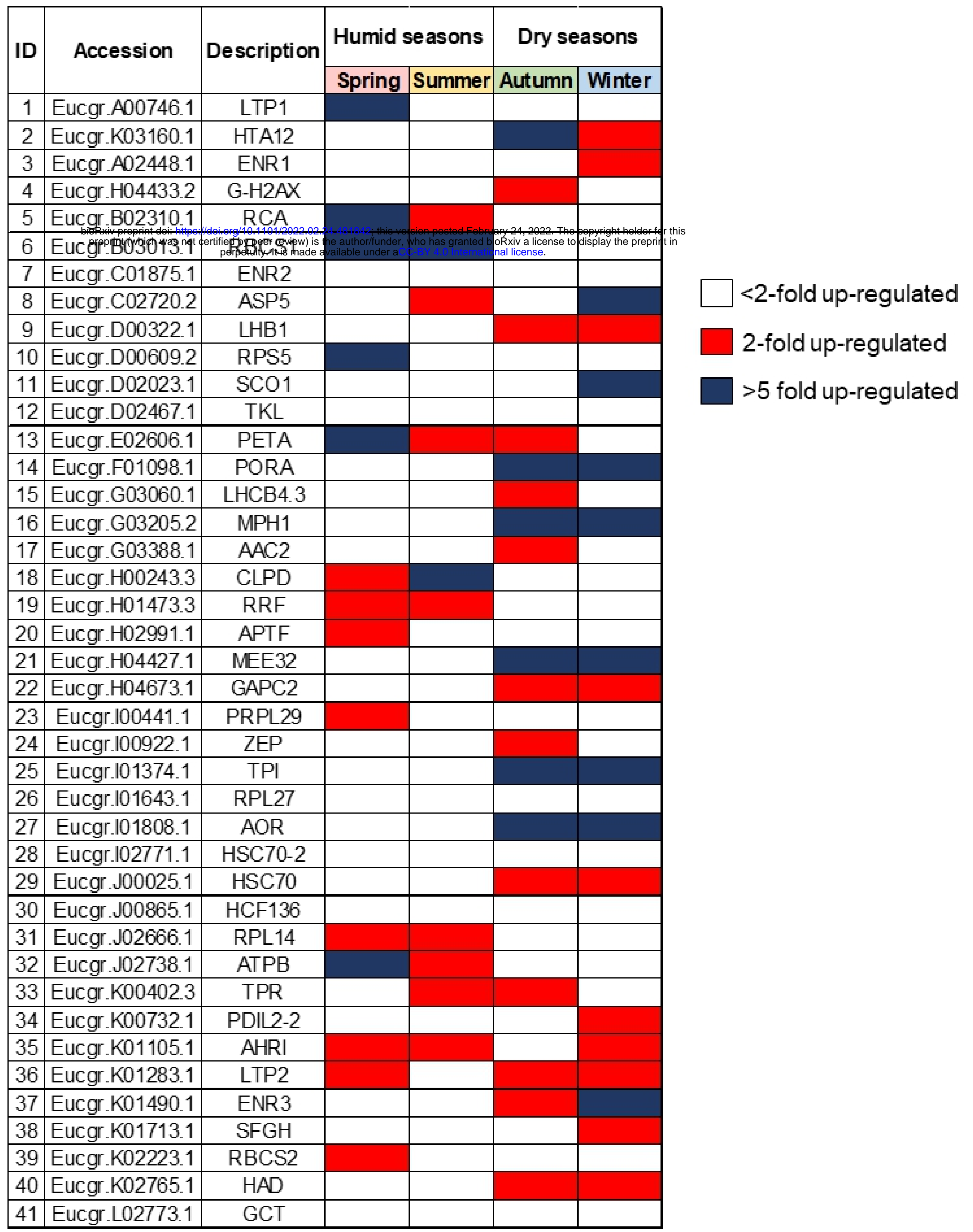

Figure 6 